\title{
Towards Deriving Differences in how Wh movement and QR are Pronounced $^{\text {负 }}$
}

\author{
Kyle Johnson ${ }^{\mathrm{a}}$ \\ ${ }^{a}$ Linguistics Department, South College, University of Massachusetts, Amherst, MA 01003, USA
}

\begin{abstract}
In English, Wh Movement oftentimes has the effect of letting the phrase moved be spoken in a higher position than where it originates. That position seems to get mapped onto a portion of the resulting string that is to the left of the original position. Quantifier Raising in English, by contrast, tends to require the phrase that is moved to be spoken in the position it is moved from. And when there is material that is spoken in the higher position, that material gets mapped onto a portion of the resulting string that is to the right of the lower position. I attempt to explain these differences. The explanation comes from taking the movement operation to be remerge (giving rise to multidominant phrase markers) and letting determiners spread across distant syntactic positions but get mapped onto one word.
\end{abstract}

Keywords: movement, questions, quantifiers, quantifier raising, wh movement, semantics, linearization, multidominance, merge, reconstruction

\section{The Problem}

Movement is a relation widely used to model certain cases of semantic displacement. In cases of constituent questions like that in (1), for example, which dish is understood to be the object of eat and we therefore expect it to fill the syntactic position that would normally follow the verb.

(1) Which dish should no one eat?

Movement is invoked to fulfill this expectation. It establishes a relationship between which dish and the object position by creating a silent variable in the object position and forcing which dish to bind it. A similar situation arises in (2).

(2) A marble filled every hole.

\footnotetext{
This paper started as a talk at Leiden University in March of 2010 and had a very helpful boost from the audience at the Seoul International Conference on Generative Grammar at Konkuk University in August 2010. Much of the thinking was borne in seminars I gave at MIT in the Fall of 2008 and at UMass in the Fall of 2009. It owes a great deal to the audiences at these venues. And for helping me understand hard things and rescuing me from blunders, I am especially indebted to Seth Cable, Lyn Frazier, Satoshi Tomioka, Jeroen van Craenenbroeck, Paul Elbourne, David Pesetsky, Irene Heim, Lisa Matthewson, Rajesh Bhatt, Lyn Frazier and Keir Moulton. Danny Fox deserves special mention for doing all this even when I was taking potshots at his work. You and I were very lucky to have two excellent reviewers read the original submission. The paper, particularly its readability, has been vastly improved by their hard work.
} 
In this case, the denotation associated with every hole is applied at a position different than its spoken position. Where it is spoken is understood to be a variable bound by every hole, and every hole is understood to be in a position that puts a marble within its scope. Movement, then, gives (1) and (2) the representations in (3).

(3)

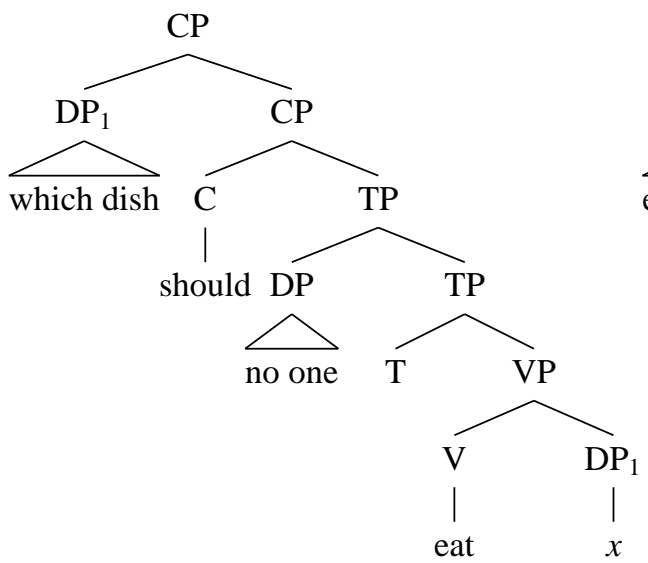

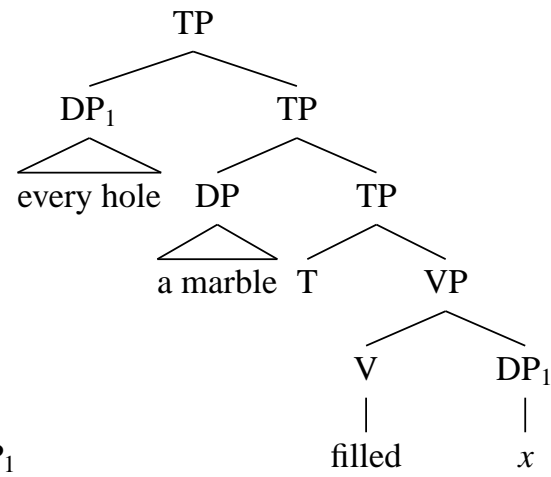

Although the kind of semantic displacement that we find in these two examples can be modeled with the same operation, the differences in how they are expressed phonologically should give us pause. In the case of Wh Movement illustrated by (1), the moved phrase is spoken in the binder position, and the variable is silent. In the case of Quantifier Raising (QR), illustrated by (2), the moved phrase is spoken in the position of the variable, and the binder position is unspoken. There have been attempts to explain this difference, but none do better than stipulate it. This raises the reasonable suspicion that these phenomena do not have the same source; they are not both instances of movement. If the mechanism that gives quantificational arguments scope wider than expected from their spoken position is different than the mechanism that allows interrogative phrases to bind silent variables, there would be no expectation that they should bring the same phonological outcome.

That is a sensible response to the issue, but not the one explored here. Instead, I will offer a definition of movement that derives the difference in where the moved item gets spelled out in QR and Wh Movement. It will also capture two other differences between QR and Wh Movement that concerns how they get expressed. To see these differences, we need first to appreciate why using movement to model both $\mathrm{QR}$ and Wh Movement is desirable. That is the goal of the following section.

In that section, I will also sketch what I believe is the presently standard definition of movement. It harbors certain stipulations that we should rid ourselves of. One of these concerns how movement leaves one of the two positions it involves with no phonological content. Jairo Nunes has provided an explanation for this property that rests on one of these stipulations. That stipulation, I will suggest, can be removed if we adopt a model of movement that involves multidominance. The moved item will be represented as one term given two sisters.

The other stipulation comes in the semantic interpretation of movement relations like those that QR and Wh movement illustrate. In order to capture the fact that movement sets up a binderbindee relation, the movement rule is standardly imbued with a process that inserts a variable into the lower position. I will replace that process with a reconception of what movement is. Movement of DPs, I will argue, is the result of putting the terminals in a DP together in such 
a fashion that they spread across a sentence. The DPs that do this in the cases of QR and Wh Movement are kinds of definite descriptions; those definite descriptions form the variable part of the movement relation. For morphological reasons, these definite descriptions form a constituent with an operator. In the case of Wh Movement, this operator is the question morpheme. In the case of $\mathrm{QR}$, this operator is the quantifier. While the morphology requires that these operators be in construction with the definite description, their semantics requires that they be merged in positions that are distant from those definite descriptions. These conflicting requirements are met by letting the relevant constituents stand in more than one position in the phrase marker. This is movement.

In the case of Wh Movement and QR, then, I will present a picture that lets these movement operations arise as a way of resolving conflicting requirements made by the morphology and the semantics. But the morphological and semantic requirements are slightly different in these two cases, and this will have an effect on the details of their resolution. One of these, perhaps surprisingly, is how Wh Movement and QR lead to phonological representations.

Let's begin, then, by considering how movement theories presently model QR and Wh Movement.

\section{Copy Theory}

Two properties a theory of movement should deliver are (4).

(4) If movement relates $\alpha$ to positions $\pi$ and $\pi^{\prime}$, then

a. TERSENESS:

All of $\alpha$ is pronounced in just one of $\pi$ or $\pi^{\prime}$, and the other position is left with no phonological content.

illustration:

i. Which solution to a problem does she require?

ii. * Which solution to a problem does she require solution to a problem?

b. Semantic Displacement:

Some of $\alpha$ may be semantically interpreted in the position it is not pronounced in. illustration:

i. Which story about her ${ }_{1}$ should none of the women forget? $^{2}$ ?

ii. * Which story about her ${ }_{1}$ should someone who knows none of the women ${ }_{1}$ forget?

Terseness expresses the reason why the operation is called "movement." The moved term changes its position: it gets spelled out in just one of the positions it is related to and the other position goes empty.

Semantic Displacement refers to the fact that material within a moved phrase behaves as if it can be semantically evaluated in the position the phrase is not pronounced in. In the illustration of Semantic Displacement above, this is indicated by the fact that a pronoun within the moved wh-phrase can be bound by a quantificational expression that c-commands the position from which the wh-phrase moved. These kinds of Semantic Displacement often go by the name of "reconstruction." Contrary to what TeRseness indicates — and "movement" names — a moved phrase is, in some sense, still in its pre-moved position. What a successful definition of movement must explain, then, is why these seemingly contradictory properties coöccur. A moved term behaves semantically like it is in a position that it is prevented from occupying phonologically. 
Chomsky's (1995) "copy theory" of movement has elements that allow for just such an explanation, and I will therefore start with it. We can define the copy theory of movement with (5).

(5) MOVE $\alpha={ }_{\text {def. }}$

a. copy $\alpha=\alpha^{\prime}$, where $\alpha^{\prime}$ is identical syntactically to $\alpha$, and

b. $\operatorname{MERGE}\left(\alpha^{\prime}, \beta\right)$

(6) $\operatorname{MERGE}(\alpha, \beta)=_{\text {def. }} \quad \gamma \quad$ (linear order not determined)<smiles>[B]C[Te]</smiles>

The key ingredient is the copy operation, which allows both positions related by movement to contain an image of the phrase being moved. (7) illustrates how it produces instances of Wh Movement.

(7)
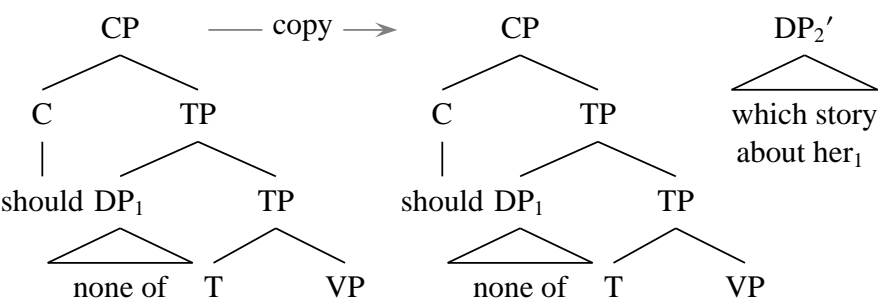

the women
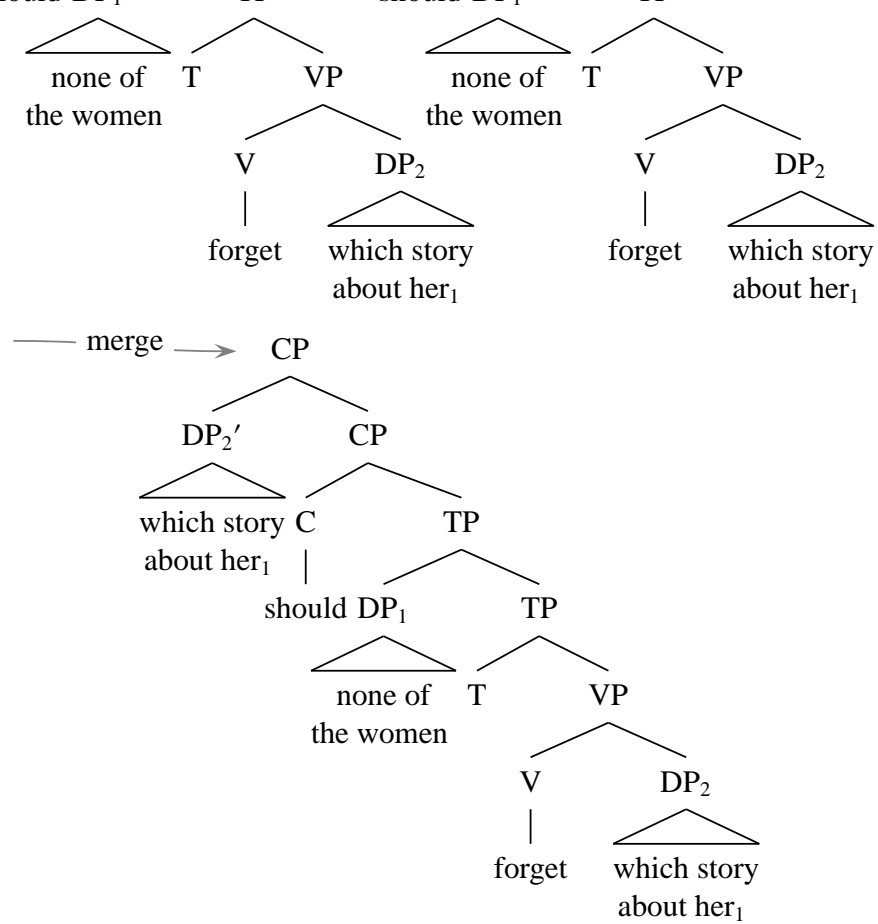

Semantic Displacement is now directly accounted for. There is something in the unspoken position - a copy - whose denotation matches that of the phrase we see in the spoken position. The pronoun in (7) has a copy that is in the c-command domain of its binder.

Nunes $(1999,2004)$ suggests a way in which the copy operation can be seen as the source of Terseness as well. He combines the copy theory of movement with a linearization scheme 
that has the effect of enforcing Terseness. His account has four parts. First, he has a linearization algorithm that interprets phrase markers and produces from them a linear ordering of the words therein. For this he adopts the system in Kayne (1994), which includes the following two constraints on a linearization.

(8) For every distinct terminal $x$ and $y$ in phrase marker $P$,
a. either $x<y$ or $y<x$
(Totality)
b. not $(x<y$ and $y<x)$
(Antisymmetry)

(Kayne, 1994, (1): p. 4)

A linearization is a set of pairs ordered by " $<$," the precedence relation. What Totality and Antisymmetry require is that every terminal in a phrase marker be put into such an ordered pair with every other terminal in that phrase marker, and that no inconsistent orderings arise thereby. Nunes suggests a slight revision to these constraints that is designed to account for certain exceptions to Terseness. The revision is to have the constraints operate not on terminals, but on the lexical items that the terminals map onto. (8) becomes (9).

(9) For every distinct lexical item $x$ and $y$ in phrase marker $P$,
a. either $x<y$ or $y<x$
(Totality)
b. not $(x<y$ and $y<x)$
(Antisymmetry)

These two versions have different outcomes when more than one terminal maps onto one lexical item. We will also need these constraints to operate on lexical items and not terminals, so I will adopt Nunes's modification.

The first part of Nunes's explanation for TERSENEss, then, is a linearization algorithm that produces orderings which obey Totality and Antisymmetry. The second part is the hypothesis that copies of terms are not distinct in the sense that these constraints require.

(10) $\pi^{\prime}$ and the term it was copied from, $\pi$, are not distinct for Totality and Antisymmetry.

His proposal is that the copies produced by movement are identical terms, as far as the linearization algorithm is concerned. This will cause the linearization operation to create inconsistent linearizations for the items that are in the moved phrase. In particular, it will form violations of Antisymmetry. Let's consider a concrete example to see how. Wh Movement can form a representation like (11).

(11)

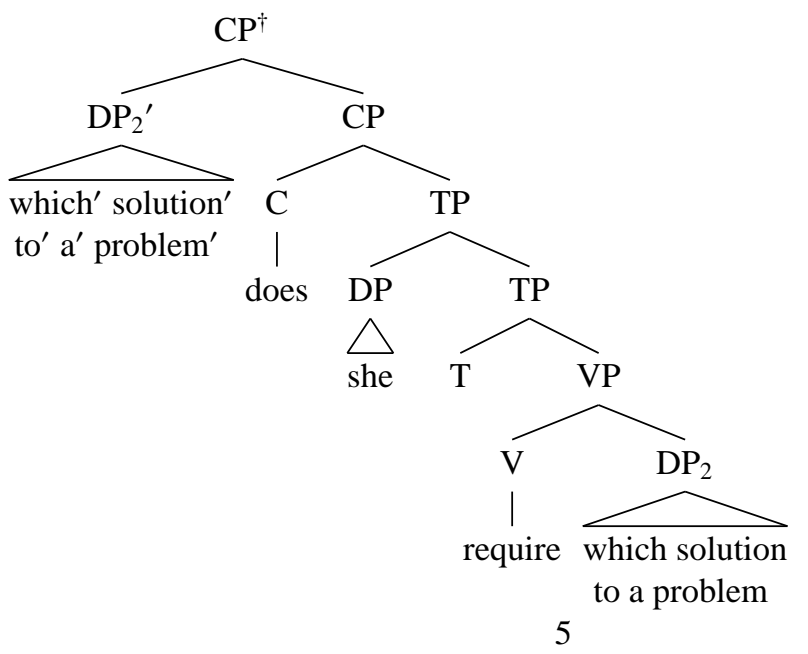


All of the lexical items in the moved phrase will gain positions in the linearization by way of their positions in both copies. Each of the lexical items in the moved DP will be assigned positions that make them precede the rest of the lexical items in CP by virtue of the position the higher copy has (Specifier of CP), but they will also be assigned positions that make them follow the rest of the lexical items in CP by virtue of the position the lower copy has (complement of require). As a consequence, the linearization procedure will produce ordered pairs that include those shown in (12).

(12) $\left\{\right.$ which $^{\prime}<$ require, solution' $<$ require, require $<$ which, require $<$ solution, ... $\}$

If copies are not distinct from the things they are copied from, then an ordering that includes (12) will violate Antisymmetry: which' < require and require < which is a violation, for instance.

What (10) in combination with the copy theory of movement does, then, is make most sentences with movement in them unlinearizable. ${ }^{1}$ The third part of Nunes's system is responsible for creating well-formed linearizations. For this, he adopts a deletion process that he calls "Chain Reduction.” I'll formulate that process as (13).

\section{(13) Chain Reduction}

Remove from a linearization all ordered pairs that involve $\alpha$, where $\alpha$ is either a copy or a term copied.

Chain Reduction can apply iteratively until it has reduced the ordered pairs in a linearization to those that obey Antisymmetry and yet still honor Totality. ${ }^{2}$ It's Chain Reduction, then, that is responsible for producing linearizations in which TERSENEss arises.

The fourth and final component to Nunes's proposal determines which copies get removed and which end up pronounced. The heart of his idea is that it is those copies that contain information about the feature values that are responsible for driving the movement in the first place that resist being deleted. He adopts the view that movement is generally invoked to put a copy of a phrase bearing certain features into a position in which those features are checked. It's that copy, with the checked features, that resists the action of Chain Reduction. What this derives is the generalization that a moved phrase is pronounced in the position assigned by the linearization procedure to the higher of two copies. Movement is overt.

This system has a nice way of accounting for certain cases of movement in which Terseness does not arise. In Vata, for instance, a topicalized verb can be pronounced in both of its positions. (14) is an example of this from Koopman (1984).

$$
\begin{aligned}
& \text { nḡ̄nच̀ ̀̀ wà nā ̀̀ kà ngónú à } \\
& \text { sleep you want NA you FUT-A sleep Q } \\
& \text { 'Do you want to sleep?' }
\end{aligned}
$$

(Koopman, 1984, (2a): 154)

\footnotetext{
${ }^{1}$ I say "most," because sentences in which the movement is string vacuous, that is does not "cross" anything, will not produce violations of Antisymmetry. For these cases we'll need something else.

${ }^{2}$ In fact, Nunes describes Chain Reduction as though it can apply to phrases, instead of to the words that make up those phrases. This raises questions about what Chain Reduction is that my formulation doesn't. Nunes suggests that his Chain Reduction is a kind of ellipsis, but if so it does not seem to be of a kind with the other forms of ellipsis that English houses. The difference between how Nunes conceives of Chain Reduction and how I've rendered it will not matter here, as I am going to abandon Chain Reduction altogether.
} 
Here "ngonひ" ('sleep') has been moved and is pronounced in both its higher and lower positions. Nunes argues that this is because the verb is part of a larger word in its higher position. It is part of a Focus head. There are, indeed, morpho-phonological differences in the pronunciation of the verb in its two positions which suggest that it is not the same "word" in both spots. In the lower position the verb carries its lexical tones, but in its higher position, it bears the midtones that we could associate with the focus head. For these reasons, Koopman and Nunes ascribe a structure roughly like (15) to (14).

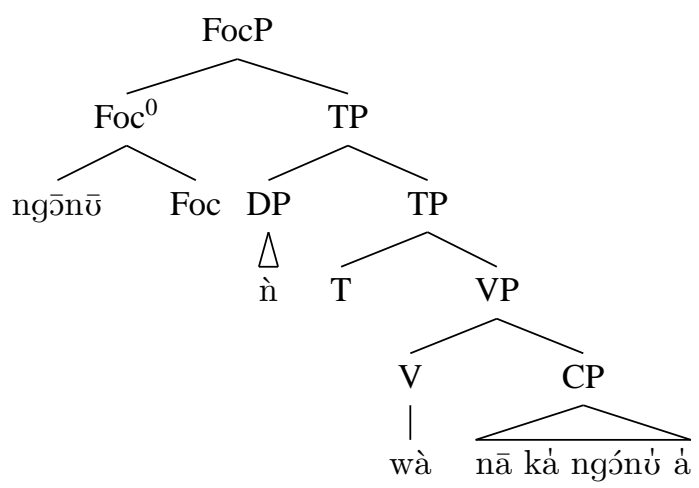

Because the linearization algorithm, and the constraints it obeys, see only lexical items, and not the terminals that make them up, the higher occurrence of "nḡ̄n̄" will not be among the ordered pairs that the linearization algorithm produces. Instead, $\operatorname{Foc}^{0}$ will be among those ordered pairs. There will consequently be no violations of Antisymmetry that involve the higher occurrence of "nḡ̄n $\bar{\mho} "$ and the lower occurrence of “nḡ̄nच̄." Nunes's system, then, does an excellent job of explaining Terseness. It explains both why it arises and where it does.

The key ingredient in accounting for both Semantic Displacement and Terseness is the notion of "copy." The copy theory of movement, then, explains why these two properties arise jointly in cases of movement.

Let's consider now how the copy theory of movement produces QR. One of the situations in which QR can be seen arises when a quantificational object contains an elided VP whose antecedent is the VP the object sits in. This can happen when a quantificational object comes with a relative clause, as in (16).

(16) She read every book that I did $\Delta$.

" $\triangle$ " marks the spot where a VP has elided. That VP is understood to be "read $x$," which, apparently, is how the VP spoken as read every book that I did gets semantically interpreted. QR is responsible for producing this interpretation for that VP. QR causes every book that I did to be interpreted higher than where it is spoken, and puts a variable in the position that the every-DP is spoken.

I will concentrate on what can be learned about QR in these contexts of so-called Antecedent Contained Deletions (ACD), and adopt the account of them in Fox (2002). On Fox's analysis, ACD is licensed when the relative clause containing the ellipsis has extraposed from the antecedent for that ellipsis. ${ }^{3}$

${ }^{3}$ The original argument for using extraposition structures as the source for ACD is Baltin (1987). 
(17) She [vp read [DP every book ] ] (yesterday) [cP that I did $\Delta$ ]

Fox ${ }^{4}$ argues that these sorts of extraposition operations are the result of "late merging" a clause into a QR'd DP. (I will henceforth adopt the convention of using a shaded font to indicate material that is not pronounced.)
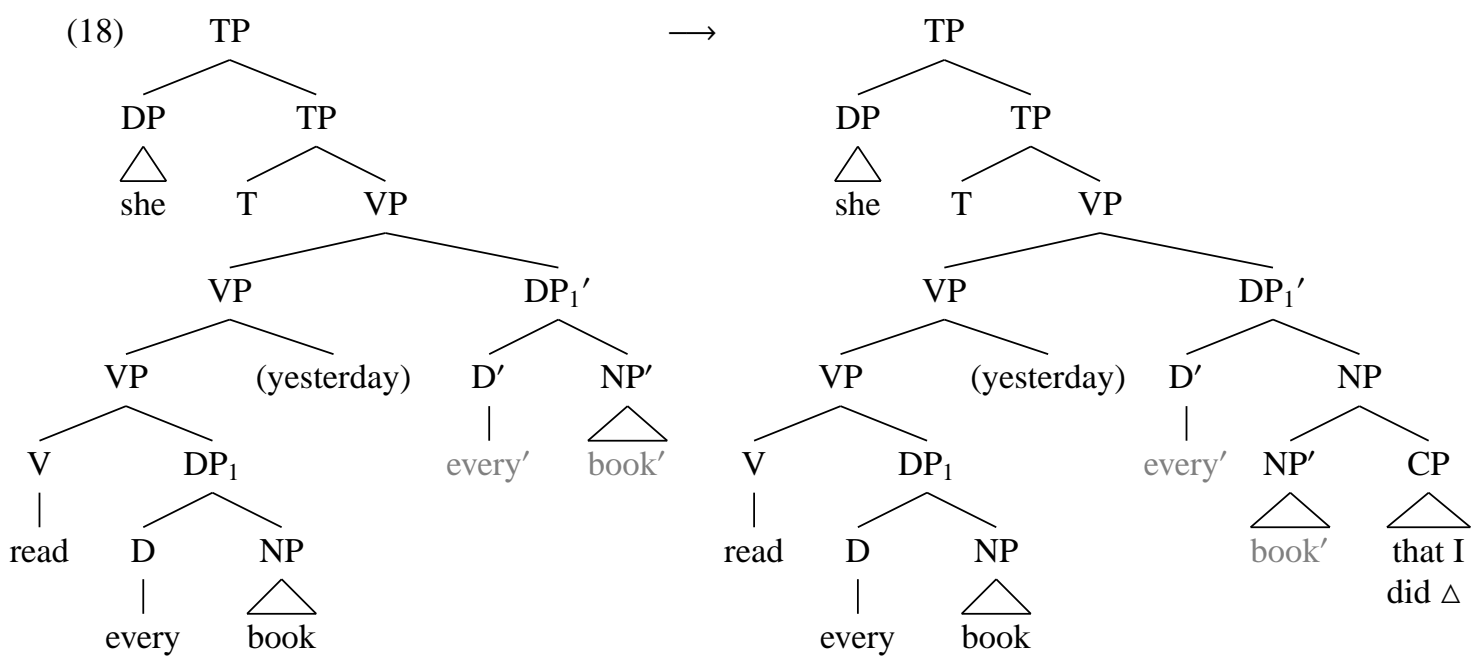

Movement produces a copy of the object DP and then merges that copy into a position outside the VP which serves as antecedent to the ellipsis. Unlike Wh Movement, this higher copy goes unpronounced and, instead, the lower copy is spoken. Into the higher copy, however, is merged a relative clause containing the elided VP, and this relative clause is pronounced in the position occupied by the higher copy of QR. Despite the differences in how QR and Wh Movement get pronounced, using the same movement operation for them both provides a simple account of extraposition from NP and, with it, a good account of ACD.

We can now see another difference between QR and Wh Movement: when material in the higher copy in Wh Movement is pronounced, that material gets linearized so that it precedes everything else in the clause it is dominated by. But when material in the higher copy of QR is pronounced, it follows everything else in the phrase it is dominated by. Wh Movement goes to the left, but QR goes to the right. We have, then, two differences in how QR and Wh Movement get pronounced that should be understood.

(19) Differences in Pronunciation

a. The material in the higher copy of Wh Movement is usually pronounced. Only material late merged into the higher copy of $\mathrm{QR}$ is pronounced.

b. When material in the higher copy of Wh Movement is pronounced, it precedes the lower copy. When material in the higher copy of QR is pronounced, it follows the lower copy.

\footnotetext{
${ }^{4}$ And see also Fox and Nissenbaum (1999) and Nissenbaum (2000b).
} 
The only attempt to derive this that I am aware of is Fox and Pesetsky (2009). I will propose an alternative, but I don't see yet how to choose between them. ${ }^{5}$

One of the most interesting pieces of support for Fox's analysis of ACD is the contrast in (20), from Tiedeman (1995).

(20) a. * I said that everyone you did $\Delta$ arrived.

b. I said that everyone arrived that you did $\Delta$. $\Delta=$ said that $x$ arrived

(Fox, 2002, (35b), (36b): 77)

It's examples like these that support the hypothesis that where the relative clause is pronounced determines where the ellipsis it contains gets resolved. Extraposition has not occurred in (20a), and as a consequence the relative clause is spoken within the VP that should serve as antecedent for the ellipsis it contains. If the relative clause must be semantically interpreted in this position, the ellipsis cannot be resolved. In (20b), by contrast, the relative clause has extraposed to a position outside the antecedent VP. This example gets the representation in (21).

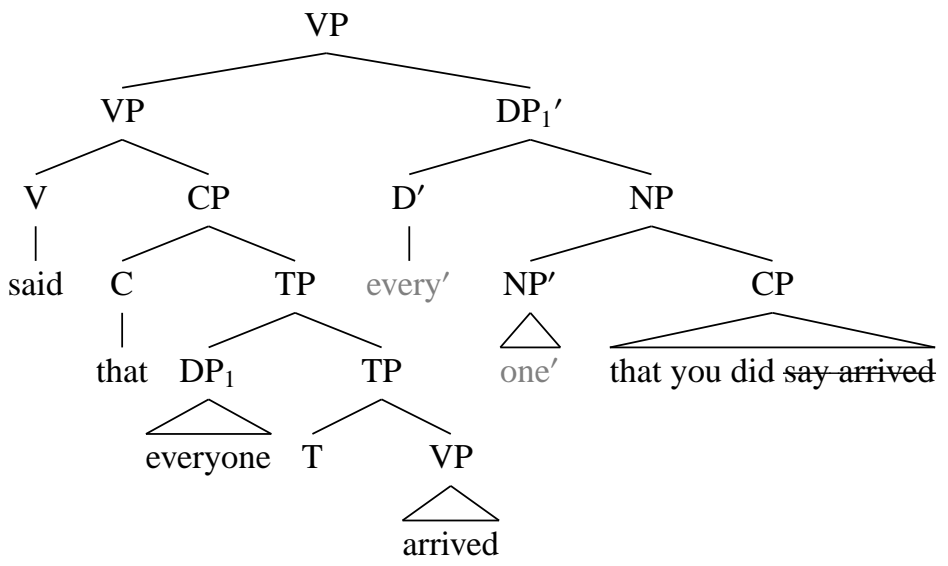

If the relative clause is semantically interpreted in the position it is spoken in in (21), the ellipsis will, correctly, be resolved.

Hidden in this example, however, is yet another difference between QR and Wh Movement. The account just reviewed assumes that the only way to produce the string in (20a) is with a representation in which the relative clause is interpreted inside the antecedent for the ellipsis. But that assumption requires $\mathrm{QR}$ to differ from Wh Movement with respect to where pronounced material gets semantically interpreted. To see that, consider a derivation in which the relative clause is part of the lower copy, and therefore maps onto the string in (20a). Let QR then move the subject and its relative clause into a higher position, one that puts the elided VP outside of its antecedent, as in (22).

\footnotetext{
${ }^{5}$ The leading idea in Fox and Pesetsky (2009) is that the linearization procedure is sensitive to the order in which phrases are merged to the phrase that projects. Roughly speaking, in a head initial language, when one phrase, $\alpha$, merges to another, projecting phrase, $\beta, \alpha$ will follow $\beta$ unless $\alpha$ is the last phrase to merge to $\beta$. When this principle is hooked onto certain assumptions about how derivations with QR go, the rightwardness of extraposition follows. A virtue of this theory is that it derives this effect from a more general principle of linearization that has its own virtues: it generally gets things linearized correctly in English, for instance. My proposal doesn't have that virtue.
} 
(22)

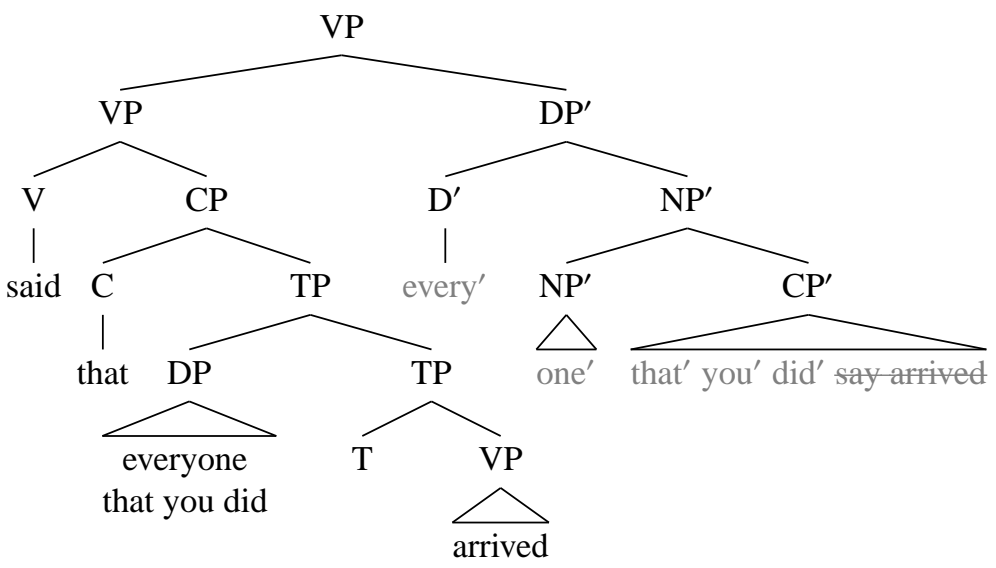

This representation is ill-formed only if the relative clause in the lower copy must be semantically interpreted. But as long as there is a copy of the relative clause in the higher position, nothing requires that this, spoken, relative clause be semantically interpreted. To block this representation, then, we must add a requirement that the spoken relative clause be semantically interpreted.

But when we consider Wh Movement, we see that a relative clause in the spoken copy need not be semantically interpreted. In an example like (23), for instance, the relative clause in the higher copy is not semantically interpreted when she is interpreted as a variable bound by no woman.

(23) Which book that she wrote should no woman $_{1}$ forget?

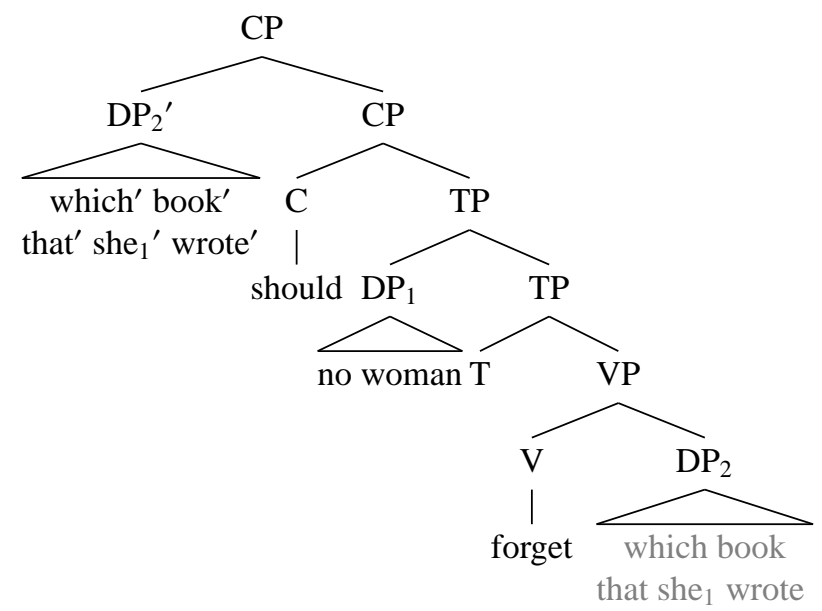

For she to be bound by no woman it must be c-commanded by no woman. Because only the she in the lower relative clause clause is c-commanded by no woman, only that relative clause can be semantically interpreted. For (23) to be well-formed semantically, then, the relative clause in the higher copy must not be semantically interpreted. What we learn from this example is that not everything in the spoken copy of Wh Movement need be semantically interpreted. What we learn from (20), by contrast, is that everything in the spoken copy of QR must be semantically interpreted. This, then, is the last of the differences between $\mathrm{QR}$ and Wh Movement to be derived. 
Altogether, then, we have the three differences between QR and Wh Movement in (24).

(24) a. The higher copy of Wh Moved material is pronounced, but the lower copy of QRd material is.

b. Material in the higher copy of Wh Movement is linearized to the left of the other copy. Material in the higher copy of QR is linearized to the right of the lower copy (if it is pronounced in that position).

c. QR'd material must be semantically interpreted where it is spoken, but Wh moved material is able to be semantically interpreted in only its unspoken position.

All three differences have to do with how the material in a movement relation is mapped onto a string. We want something that forces QR'd material to be interpreted where it gets linearized, but allows Wh Movement to linearize material in a place where it's not interpreted. We want something that linearizes the higher copy of a Wh Movement relation to the left, and the higher copy of a QR'd relation to the right. And, finally, we want something that forces the lower copy of a QR'd phrase to be in the linearization, but allows the higher copy of a Wh Moved phrase to be linearized. We seek a difference, then, in how Wh Movement and QR work that will cause the same linearization algorithm to deliver these effects.

I will propose a way of doing that. The central idea has two parts. The first is to define "copies" in a way that derives Nunes' stipulation that the linearization algorithm treats copies as the same thing. That definition will make movement "remerge" the moved item in a second position, thereby giving a moved phrase more than one mother. Phrase markers with movement relations in them will be ones in which multidominance arises. In this regard, I am following much recent, and some old, work. ${ }^{6}$ The second part will be to work out the morphology of the movement relation. It's in the morphology that we will see a difference in Wh Movement and QR. That difference will require slightly different syntactic representations for QR'd and Wh Moved phrases, and this, I will show, can be credited with the differences in how the two operations get pronounced.

\section{Multidominance}

\subsection{Remerge and Linearization}

Nunes' method of deriving Terseness has two unwanted stipulations. One is that it requires that copies be indistinguishable. When the linearization algorithm causes one copy of something to precede a term, $\mathrm{X}$, and another copy of that thing to follow $\mathrm{X}$, this needs to be a violation of Antisymmetry. That will happen only if copies are the same thing, and so Nunes makes that stipulation. The second stipulation is that the violations of Antisymmetry which arise when copies are inconsistently ordered with something are rescued by a process that removes the phonological content from one of those copies. Both of these stipulations can be overcome by adopting a "remerge" interpretation of the copy operation. On this view, movement is simply taking a term that has already been merged into one position, and merging it into a second position.

"Move $\alpha$ " is the name given to $\operatorname{MergE}(\alpha, \beta)$, when $\beta$ contains $\alpha$.

${ }^{6}$ See, for instance, Engdahl (1980), Gärtner (1997, 2001), Nunes (2001), Starke (2001), Frampton (2004), Citko (2005), Fitzpatrick and Groat (2005) and many others. 
An instance of Wh Movement on this definition would create structures like (26).

(26) $\mathrm{CP}$

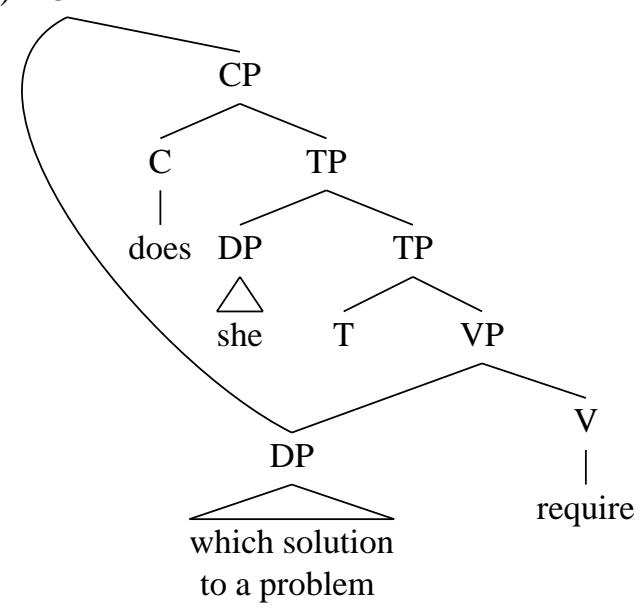

If the linearization algorithm evaluates the moved phrase in all of the positions it occupies in (26), solution will follow require, because that is what the linearization algorithm does with the contents of objects and the verbs they are the objects of, and solution will also precede require, because that is what the linearization algorithm does with the material in phrases that occupy the Specifier of a CP and everything else in that $\mathrm{CP}$. That would produce a violation of Antisymmetry, however, and so the linearization algorithm is prevented from evaluating a moved phrase in both of its positions. Totality requires that the linearization algorithm evaluate the lexical items in a moved phrase so that they emerge in at least one of their positions. Together, they require the linearization algorithm to put a moved phrase in exactly one of its positions: this is Terseness. Adopting a remerge interpretation of movement explains Nunes's stipulation that copies are indistinguishable and, at the same time, removes the need to invoke a deletion process to produce well-formed linearizations.

This way of deriving Terseness allows too many ways of avoiding violations of Antisymmetry, however. Because the linearization algorithm evaluates precedence relations for each lexical item in a phrase marker independently, it is possible to let representations like (26) satisfy Antisymmetry in different ways for each of the words in a moved phrase. For instance, the linearization algorithm could choose to produce $\{$ which $<$ she, to $<$ none $\}$ and $\{$ she $<$ solution, she $<a$, she $<$ problem $\}$ and thereby order everything in the moved phrase with respect to she in a consistent, but different, way. If that were allowed, we should expect strings like (27) for (26).

(27) a. which to does she require solution a problem.

b. to she require which solution a problem.

What is needed, then, is something to ensure that when a choice is made about how to resolve Antisymmetry for one of the lexical items in a moved phrase, that choice spreads to all the other words in that moved phrase.

I propose to do that with a constraint that will favor mapping the contents of a phrase onto a contiguous string. I'll formulate this constraint with (28). ${ }^{7}$

\footnotetext{
${ }^{7}$ This constraint can be found in Fanselow and Ćavar (2001, (56): 130).
} 


\section{(28) Contiguity}

Let $\delta$ be all the lexical items in the phrase D. Contiguity holds for D iff for every $\alpha$ that is not in $\delta, \alpha$ precedes everything in $\delta$ or $\alpha$ follows everything in $\delta$.

In the case of the moved phrase in (26), Contiguity will require that its contents remain together in the resulting string. In general, Contiguity will ensure that phrases have an image in contiguous strings. That is a desirable result generally, but it is violated when multidominance arises. In (26), for instance, the linearization algorithm will put does and she both after some of the contents of the VP (the material in the moved DP) and before some of the contents of the VP (the verb). Contiguity is violable, then. It will favor representations in which movement hasn't occurred, allowing them only when some other requirement cannot otherwise be met. To have Contiguity do the work of keeping together the terminals in phrases that have moved, we should understand more violations of Contiguity to be worse than fewer violations of Contiguity. Let us adopt (29).

(29) Let $\mathrm{L}=\left\{\sigma_{l}, \sigma_{2}, \ldots, \sigma_{n}\right\}$ be all the possible linearizations for a root node P. $\sigma$ is a grammatical linearization if:

a. $\sigma$ obeys Totality and Antisymmetry, and

b. $\sigma$ obeys whatever language particular requirements there are, and

c. there is no $\sigma^{\prime}$ that incurs fewer violations of Contiguity than $\sigma$ does.

Under (29b) fall such things as "verbs precede their complements" and "specifiers come initially in their phrases": all the conditions that give a language its particular word order. As we've seen, (29a) makes sure that the linearization includes all the lexical items in P, but does not give those lexical items positions that cause inconsistencies. To see how (29c) keeps the material in moved phrases together, compare the linearizations assigned to (26) in (30). 
(26)

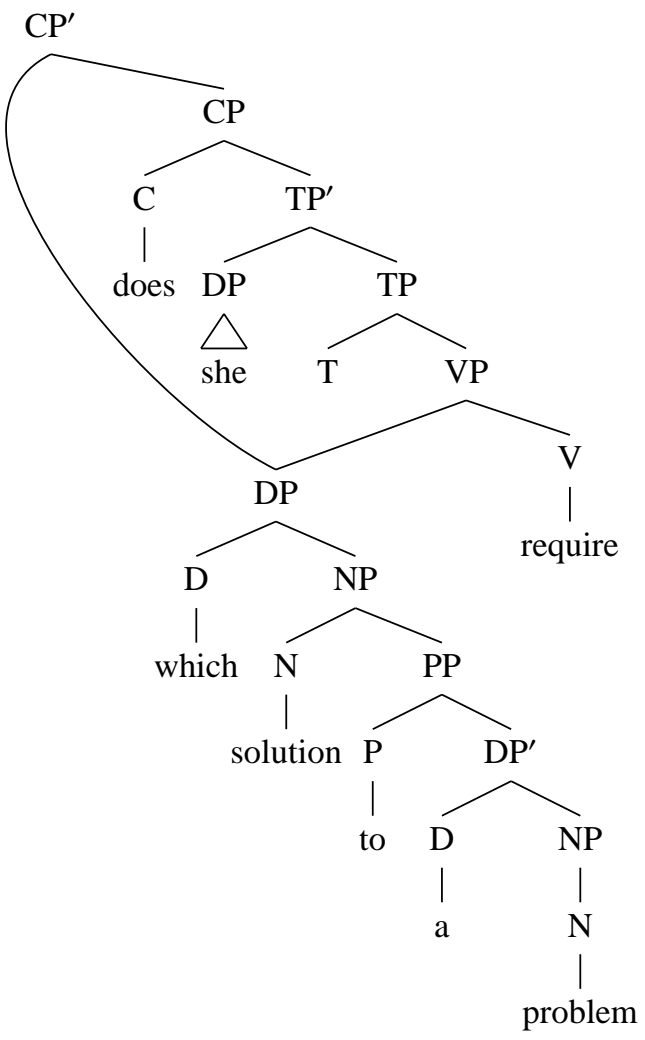

(30) a. which does she require solution to a problem

b. which solution to a problem does she require

There are five phrases that violate Contiguity in (30a): CP, TP', TP, VP and DP. These are all the phrases that she, $T$, and does precede some part of (for instance, solution), but not all parts of: not which. By contrast, there are four phrases that violate Contiguity in (30b): $\mathrm{CP}, \mathrm{TP}^{\prime}, \mathrm{TP}$ and VP. As in (30a), does, she and $T$ precede something in these phrases (namely require) but not everything in these phrases (for instance, not which). DP doesn't violate Contiguity in (30b) as it does in (30a) - because does, she, and $T$ follow everything in DP. (30b) therefore produces fewer violations of Contiguity than does (30a), and so (29c) will mark (30a) ungrammatical. In general, $(29 \mathrm{c})$ will cause all the lexical items in a phrase that has two sisters, like DP does in (26), to stick together as a contiguous substring in the linearization.

The remerge interpretation of movement preserves Chomsky's method of deriving Semantic Displacement, so we have not lost the central goal of the copy theory of movement. In cases where the moved phrase contains something that is interpreted in its unspoken position, as in (31), a multidominant representation will achieve the same result that the copy theory does. 


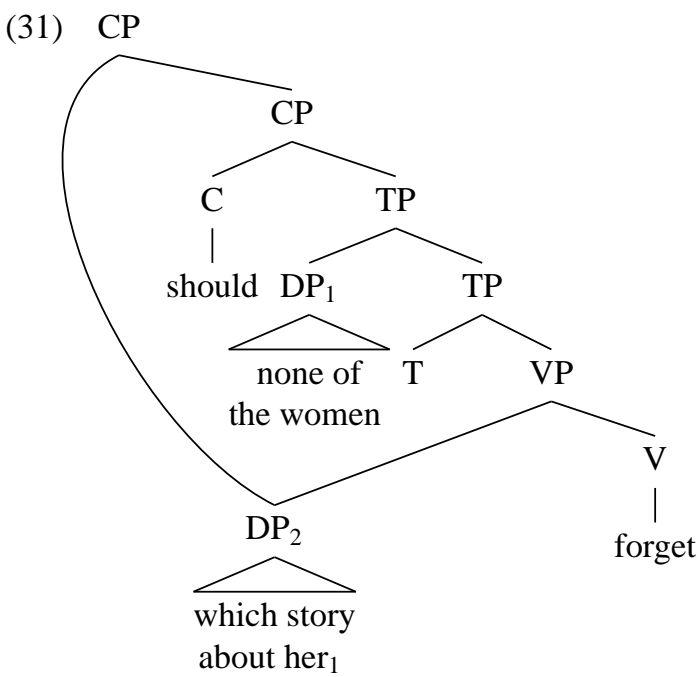

A banal definition of c-command will correctly put her within the c-command domain of none of the women.

As with the copy theory of movement, a remerge theory of movement explains why movement obeys TERSENESS and shows reconstruction effects.

\subsection{Trace Conversion}

A problematic aspect of multidominant representations is that they require the same phrase to get different semantic interpretations depending on the positions it occupies: as a variable in its lowest position and as an operator in its highest position. The previous solutions to these problems invent a semantics that does just that. In Engdahl $(1980,1986)$ and Fox (2003), for example, the phrase in its lowest position is given the denotation of a definite description - the kind of definite description that can vary with values given to some other term, like that found in (32).

(32) Every woman who owns a donkey feeds the donkey.

Fox calls this rule "Trace Conversion." 8 In the higher position, the moved phrase is given a denotation that allows it to bind the definite description it is interpreted as in the lower position.

I would like to explore ways of avoiding a system that allows the denotation of a phrase to change depending on what position it is interpreted in. Instead let's let the syntactic representations resulting from movement simply put a definite description in the trace position. That means that the phrase in the higher, binding, position must be something different. There will be two phrases that movement combines in my representations. I'll develop that idea first for Wh Movement.

\subsubsection{Wh Movement}

The leading idea is that constituent questions involve a DP that introduces a variable and a question morpheme $(\mathrm{Q})$ that binds off that variable. ${ }^{9}$ These two components are transparently

\footnotetext{
${ }^{8}$ See also Sauerland $(1998,2004)$ for a slightly different formulation of Trace Conversion.

${ }^{9}$ See Reinhart (1998), Hagstrom (1998, 2000), Kishimoto (2005), and Cable (2007, 2010b).
} 
involved in many languages. In Japanese, for instance, a morpheme on the verb marks the scope of a question, and in the position of the variable is an interrogative phrase. In (33), for instance, the question morpheme is $k a$ and the interrogative phrase is dono gakusei.

(33) (Kimi-wa) dono-gakusei-ga nattoo-o tabe-tagatte-iru-to omoimasu-ka? (you-top) which-student-nom natto-acc eat-desirous-be-C think-Q

(Which student do you think wants to eat natto?)

I propose that English constituent questions also have these two components. The interrogative phrase is the familiar "wh-phrase," and the question morpheme is phonologically silent.

Whereas in Japanese, we might imagine that the question morpheme and the interrogative phrase are independently merged into the positions that they are pronounced in, I suggest that English arranges these two parts to the question along the lines that Seth Cable has recently argued for. In Cable (2007, 2010a), he studies questions of the sort that Japanese illustrates, but his object of study is Tlingit, a Na-Dené language spoken in Western Canada and Southeastern Alaska. Like Japanese, Tlingit has a wh-determiner and another morpheme - I'll call it Q — in its questions. Like English, the wh-phrase moves overtly to the left edge of the question sentence. Interestingly, unlike the Japanese question morpheme, the Q morpheme is part of the phrase that moves in Tlingit, and not merged directly into a position marking the scope of the question. (34) illustrates. ( $x$ marks the spot from which aadóo yaagú moves.)

(34)

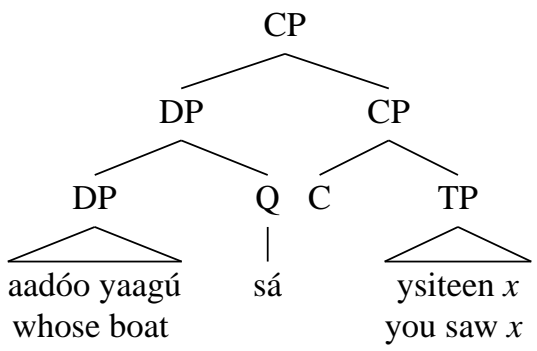

(Cable, 2010b, (67): 44)

In (34), the Q particle, sá, has merged with a DP, inside of which lies the wh-word: aadóo.

Moreover, Cable, like Kratzer and Shimoyama (2002) and Adger and Ramchand (2005), takes the Q morpheme to be in an Agreement relationship with the wh-word. He develops locality conditions on that agreement relation which partly determine where the Q particle can be merged. Very roughly, that locality condition can be described with (35).

(35) Q can agree with D only if there is no lexical word that c-commands D but not Q.

This allows the Q morpheme to attach to a DP whose Specifier contains the interrogative phrase, as has happened in (34). It also allows the Q morpheme to attach directly to the interrogative phrase, as in (36).

(36) Daa sá aawaxaa i éesh? what $\mathrm{Q}$ he.ate.it your father 'What did your father eat?'

(Cable, 2007, (58a): 73)

And it allows the $\mathrm{Q}$ morpheme to attach to a prepositional phrase containing the interrogative phrase, as in (37). (Prepositions must be understood to be among the class of words that are "functional" and not "lexical.") 
(37) Aadóo teen sá yeegoot?

who with Q you.went

'With whom did you go?'

(Cable, 2010b, (32a): 116)

But it prevents the $\mathrm{Q}$ morpheme from attaching to a phrase headed by a lexical word, like a verb, whose complement is the interrogative phrase, as in (38).

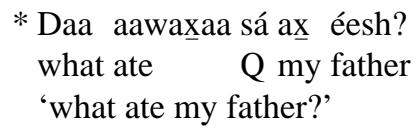

(Cable, 2008, (91b): 54)

Cable points out that this corresponds rather closely to the range of phrases that Wh Movement "pied-pipes" in English.

(39) She wondered...
a. whose boat you saw.
b. what your father ate.
c. with whom you went.
d. * ate what my father.

For this reason, he argues that in English too there is a Q morpheme merged to the phrase that moves, and that this $\mathrm{Q}$ morpheme is in an agreement relation with the wh-word. ${ }^{10}$

If we adapt this conclusion to a remerge account of movement, we could give English questions like that in (40) the representation in (41).

(40) Which story about her should no linguist forget?

(41)

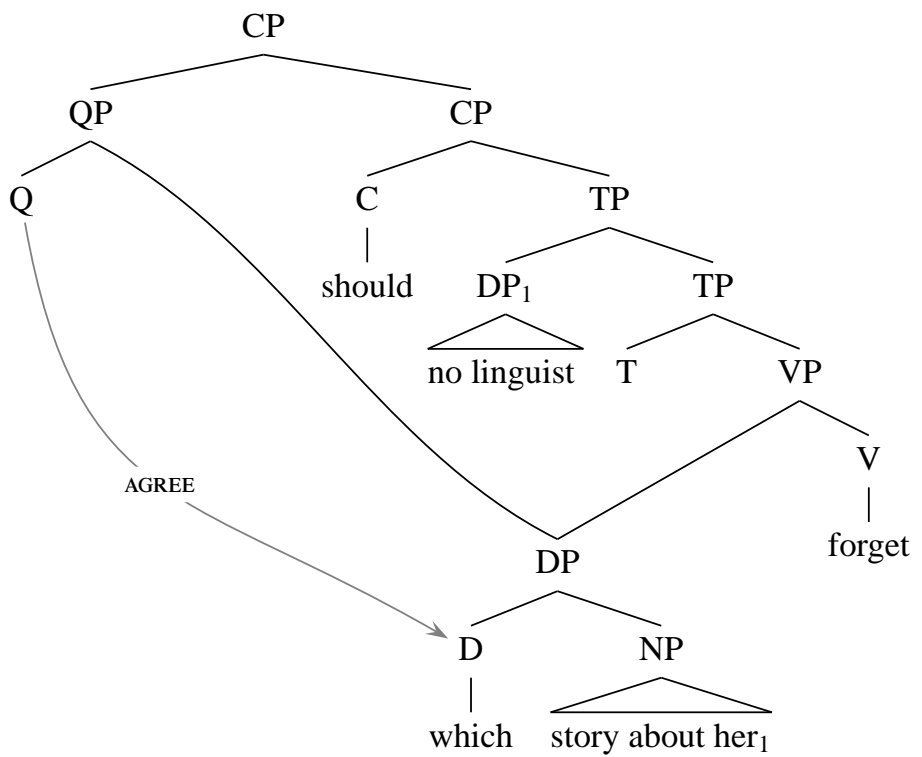

\footnotetext{
${ }^{10}$ See also Cable (2010b). This approach to Pied-Piping, and something close to the same semantics that Cable gives for it, can also be found in Sternefeld (2001).
} 
As described in the previous section, the linearization algorithm applies to these representations in such a way that phrases with two positions are allowed to be linearized according to only one of them. In (41), this means that which story about her is linearized so that is comes either in the position that English maps Specifiers of CP or in the position that English maps the direct objects of verbs. In single questions like these, English chooses the first of these options, and so which story about her will get mapped into the CP initial position.

The syntactic relationship between the Q morpheme and the interrogative phrase is different in English than it is in Japanese partly because of the Agreement relationship that holds in English. In Japanese, the interrogative phrase's morphological form does not depend on the presence of the question morpheme. When the question morpheme is not present, the interrogative phrases of Japanese get an interpretation that depends on other semantic operators. In English, by contrast, the interrogative phrase's form depends on the presence of the question morpheme - which-phrases occur only in questions - and this is due to the Agreement relation that holds between them and the question morpheme. Because of Cable's locality condition on this Agreement relation, this forces the question morpheme to merge not with the clause that gets interpreted as the question, but instead with a smaller phrase containing the interrogative phrase. This difference in the morphological expression of the question morpheme, then, is responsible for the syntactic differences in how English and Japanese represent constituent questions. ${ }^{11}$

Imagine that this is the only difference in Japanese and English constituent questions, however. Suppose, in particular, that the semantic connection between the question morpheme and the interrogative phrase is the same. ${ }^{12}$ There are a variety of ways of spelling out the semantic connection between the question morpheme and the interrogative phrase. In Kratzer and Shimoyama (2002), Hagstrom (1998), Beck (2006), and Cable (2007, 2010b), for instance, the interrogative phrase introduces Hamblin-style ${ }^{13}$ alternatives that propagate up to the question morpheme, which then operates on them. Or one could let the question morpheme be an existential quantifier that binds a choice function inside the interrogative phrase, along the lines suggested in Sauerland (1998) or Reinhart $(1998,2006)$. In what follows, however, I will develop a semantics that is more of a piece with the Engdahl/Fox analysis of movement relations so that my proposal can be more easily compared to theirs. On their analysis, the phrase in the lower position is interpreted as a kind of definite description. Under the proposal here, that will mean that the interrogative phrase will be interpreted in that way. ${ }^{14}$ I'll give a sketchy outline of how that might work.

The interrogative phrase will be a definite description that contains a variable, represented with a numerical index. As in Chierchia (1992) and Elbourne (2005), let's put this index within the determiner that heads the definite description. ${ }^{15}$ This can be fit to the multidominant representation of constituent questions in English with a representation like that in (42).

\footnotetext{
${ }^{11}$ Cable proposes other conditions that govern where the Q particles are allowed to be merged. The only ones that are relevant for us are the conditions on Agreement.

${ }^{12}$ The Q particle in Tlingit cannot have the meaning that I am associating with the question morpheme in Japanese and English. That's because this morpheme shows up in declarative sentences as well as questions. Cable analyzes the Tlingit Q particle as a choice function, which can be bound by other operators that determine whether the result is a declarative or a question. I am suggesting, then, that English has something akin to the Japanese question morpheme, but that it is deployed syntactically like the Tlingit Q particle.

${ }^{13}$ See Hamblin (1973).

${ }^{14}$ On treating the wh-phrases in English as kinds of definite descriptions, see Rullmann and Beck (1998).

${ }^{15}$ The semantics I will adopt are fashioned after an unpublished handout by Irene Heim for her course with Polly Jacobson at the LSA Institute at MIT several years ago.
} 
(42)

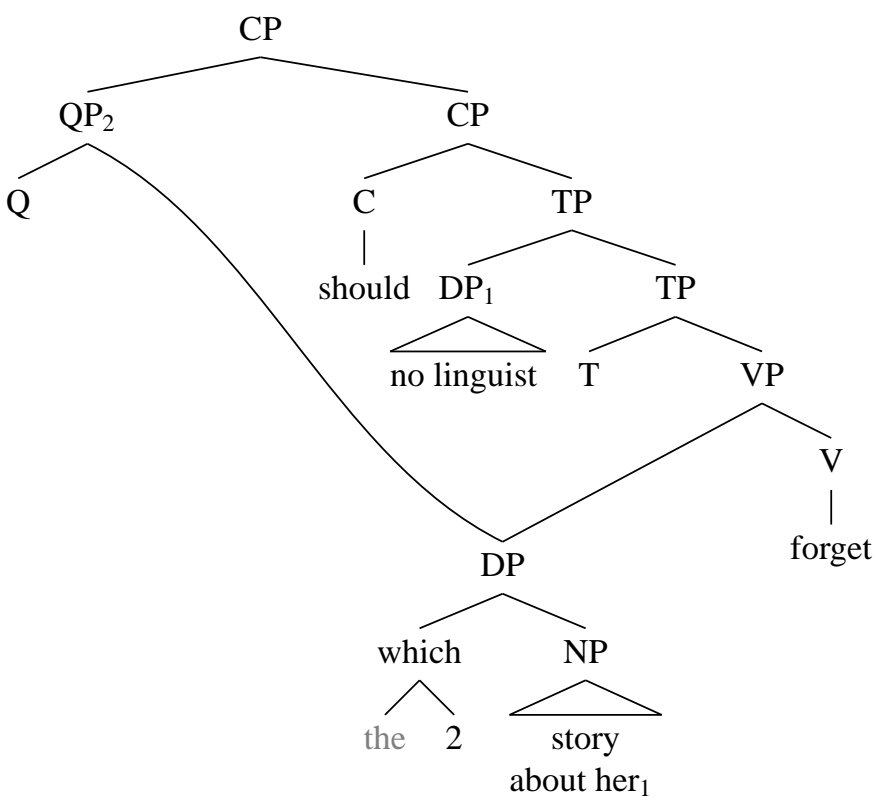

(43) $\llbracket$ the $\rrbracket=\lambda n \lambda P: n$, only if $P(n)=1$

The denotation of the makes the denotation of the phrase it heads the same as the value of the variable it comes with, and introduces the presupposition that the individual this variable refers to will be something that the predicate denoted by the NP holds of. In (42), this means that the DP will have the value given to the variable named "2" just in case that value is a story about her.

The silent $\mathrm{Q}$ morpheme binds off the variable introduced by which and produces the question meaning. A way of doing that which is built upon Karttunen (1977) is (44).

(44) $\llbracket \mathrm{Q} \rrbracket=\lambda q \lambda p \exists x: p=q(x) \wedge p=1$

Putting this together with the denotation of the which-phrase will produce representations like that in (45). The presupposition introduced by the is represented in angled brackets. ${ }^{16}$

\footnotetext{
${ }^{16}$ The semantics built here has it that questions are quantifications over individuals. In (45), for instance, the question seeks the identity of an individual "story about her." That isn't quite right, as Engdahl (1980) showed. We want this question to quantify over functions that pick out stories that vary with the values given to no linguist. We should let the variable introduced with the in (45) range over functions, then, and not individuals.
} 


$$
\begin{aligned}
\lambda p \exists x p & =\text { no linguist }_{1} \text { should forget } x \wedge p=1 \\
& <x \text { is a story about } \text { her }_{1}>
\end{aligned}
$$

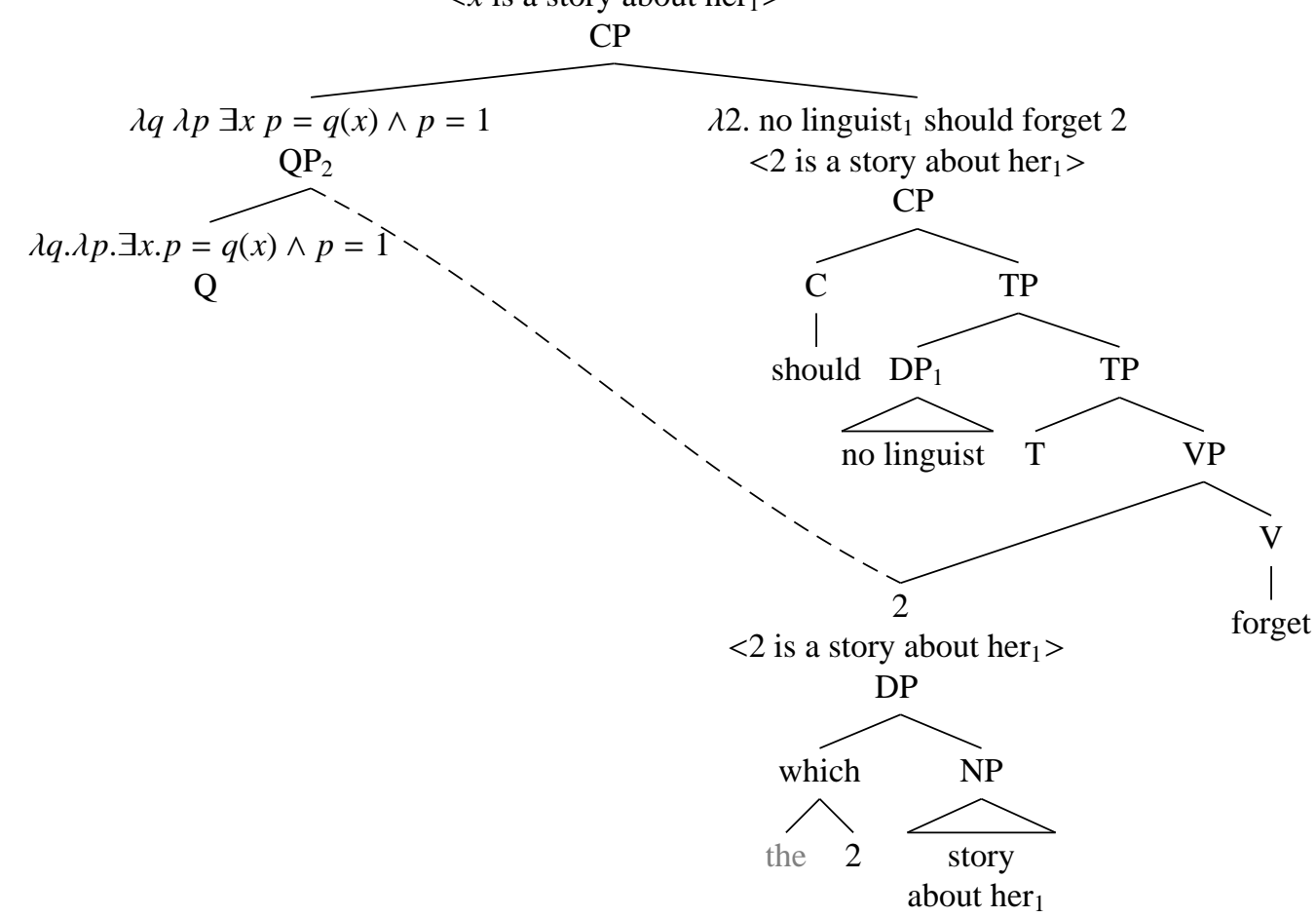

Let's assume that the index on QP is copied from the index that comes with which. This will ensure that QP binds the variable in the lower copy. We might imagine that this copying process is part of the AGREE relation that is established between Q and D. Following Heim and Kratzer (1998), $\mathrm{QP}_{2}$ and the CP it is merged with combine semantically by way of a rule that interprets the index on QP as a lambda operator that binds a variable with the same name in the CP.

Note that the denotation of Q prevents it from combining semantically with the DP (=which story about her) that it has merged with. ${ }^{17} \mathrm{I}$ indicate this with a dashed line. This requires, then, a theory of the syntax/semantics interface that does not force sisters to semantically combine. It is still necessary to force every part of a sentence to be semantically interpreted, however; there remains what Chomsky (1995) calls the Principle of Full Interpretation. In a syntax that allows multidominance, this can be achieved with (46).

\section{(46) Principle of Full InTERPRETATion}

Every term in a phrase marker must semantically combine with at least one of its sisters.

\footnotetext{
${ }^{17}$ This means that the NP parts of Wh-moved DPs will not be able to be semantically interpreted in the positions they are spoken in. This is not obviously correct, and there are several facts that suggest it is wrong. (See, for example, Barss (1986), Lebeaux (1990), Riemsdijk and Williams (1986) and Fox (1999).) I believe the solution is to let Wh Movement be successive cyclic, even when the movement is quite short, and to let the movements that intervene have a different semantics than I have given here for Wh Movement. Concretely, I suggest that we let QR feed Wh movement. This will allow a Wh-moved phrase to have more than one position in which it can be semantically interpreted: its original position, and any position to which QR has moved it. None of those positions will be the one it is spoken in, but some will nonetheless be higher than the lowest position and therefore create the illusion that it is interpreted in its spoken position. I do not have space enough to work out this proposal here, however, and so this remains an important problem with the proposal.
} 
Because Q does not semantically combine with its sister, the QP it heads will have the same denotation as Q. This, in turn, combines successfully with the CP that is its sister, and forms the question thereby. Here, then, is how the denotation associated with the question morpheme manages to combine with the $\mathrm{CP}$ that is to be interpreted as a question. Although the question morpheme merges with a phrase containing the interrogative phrase, it does not semantically compose with that phrase and, as a result, its denotation becomes the denotation of the QP it heads.

We have now ridded ourselves of anything like Trace Conversion for Wh Movement. The material in the higher position and the lower position are not the same. In the higher position is the question morpheme and in the lower position is the definite description that is interpreted as a kind of variable bound by that question morpheme. Because the question morpheme AGREES with the determiner heading the definite description, however, the definite description will also be in a phrase containing the question morpheme that resides in the higher position. That is the only way the locality condition on this AGREE relation can be satisfied. This leads to the definite description being pronounced where the linearization algorithm puts this higher phrase. But though the definite description is pronounced in this position, it is not semantically interpreted in this position. Only the question morpheme is. Wh Movement is the way English has managed to put the question morpheme and the interrogative phrase it binds in the right positions semantically while also meeting the locality condition on AGREE that holds between them. The semantics require that they be more distant than the locality conditions on AGREE tolerate, and this forces an otherwise disfavored multidominant representation to be created.

\subsection{2. $Q R$}

Let's now consider how QR can be modeled so that no recourse to Trace Conversion is needed. As with Wh Movement, let's let there be a definite description in the lower position that is bound by an operator in the higher position. Unlike the case with questions, however, the determiner in the lower position and the quantifier in the higher position will both combine semantically with the (same) NP. That is because the operator in the higher position should have the denotation normally associated with quantificational determiners. In the case of every, for instance, the operator in the higher position should mean what this universal quantifier expresses. I'll represent this higher operator with $\forall$. (47) is, roughly, what this operator denotes.

(47) $\llbracket \forall \rrbracket=\lambda P \cdot \lambda Q \cdot \forall x \cdot P(x)=1 \rightarrow Q(x)=1$

(47) requires $\forall$ to semantically combine first with the NP in the quantificational DP and then with another predicate, one that corresponds to the scope of the quantifier. Unlike Wh Movement, then, QR does not put a DP in two positions, but instead puts an NP in two positions, as indicated in (48). ${ }^{18}$

\footnotetext{
${ }^{18}$ The idea that the quantificational part of quantificational DPs can be expressed syntactically in a position different from where the quantificational DP is, is an old one. It has a variety of variants, which include Williams (1986, 1988), Beghelli (1993, 1995), Kitahara (1996), Reinhart (1997), the papers in Szabolcsi (1997), Sauerland (1998), Johnson (2000a,b), Sportiche (2003), Kratzer (2005), and Butler (2004).
} 
(48) A student read every paper yesterday.

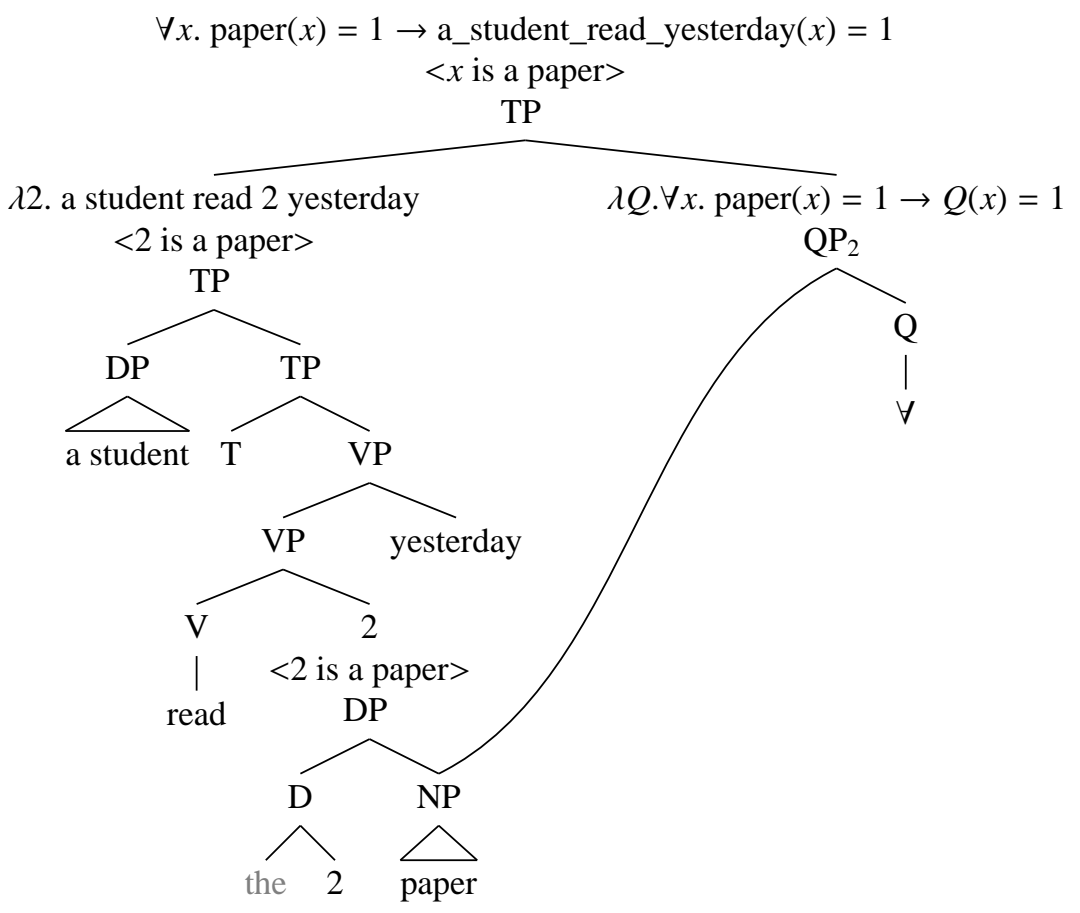

In the lower position is the same definite description that I ascribed to questions. ${ }^{19}$ It is interpreted as a variable, and introduces the presupposition that this variable refers to things that are papers. The NP part of this definite description is also part of the higher quantificational phrase. The higher quantificational phrase binds the variable introduced by the definite description, and has the same meaning that we would have credited every paper with. From a semantic point of view, this is identical to what Danny Fox's Trace Conversion rule produces for QR.

The representation in (48) gives the right syntax-to-semantics mapping, but it isn't obvious how it will produce the correct strings. Just like Wh Movement, it's necessary to find a way of mapping the determiner in the lower position and the operator in the higher position onto one lexical item. In the case of questions, this was done with AGREE; the question morpheme expresses itself by determining how the definite determiner in the lower phrase gets pronounced. But that cannot be what happens in (48). AGREE requires of the two terms it involves that one c-command the other, but neither of D or Q c-commands the other in (48). There must be some other way in which the and $\forall$ get spelled-out as every in (48).

I suggest that D and Q get expressed as one lexical item by way of a morphological process that allows two terminals to be combined into one vocabulary item. ${ }^{20}$ This process shows up in a

\footnotetext{
${ }^{19}$ That certain quantifiers come with hidden definite determiners in English has been argued in Matthewson (2001). The proposal here differs from hers in how the definite determiner is situated relative to the quantifier, and consequently, in the semantics used. It may be that the general direction her arguments point could, however, be preserved.

${ }^{20}$ Seth Cable points me to the fact that one of German's quantificational determiners, jeder, is transparently made from the universal quantifier, je, and the definite determiner, der. Sauerland (2003) gives an analysis of jeder that, like my proposal here, semantically decomposes the je and der parts. Unfortunately, his treatment isn't compatible with the reänalysis of Trace Conversion that I have adopted.
} 
variety of ways. It is responsible for mapping a preposition and determiner onto one lexical item in certain contexts in German (and other IndoEuropean languages), for instance, as in (49).

(49) an dem Tisch $\rightarrow$ am Tisch

on the table $\rightarrow$ on.the table

And it has been employed to model syncretism as well. The way that tense and $\phi$ features are mapped onto (seemingly) undecomposable morphological forms in the paradigm for English be, for instance, can be modeled by letting the tense and $\phi$ features "fuse" into a single bundle that is then matched to a vocabulary item. These processes go by various names, and there seem to be slight differences in the conditions under which they may operate. ${ }^{21}$ Across all these cases, though, there is a similar locality condition on the two terminals that combine: they must be so close together that, under normal circumstances, they would be adjacent in the string. Let us simply adopt this descriptive consequence as a well-formedness condition on fusion, as I will call the process that brings $\mathrm{D}$ and $\mathrm{Q}$ together into one word.

(50) $\mathrm{X}$ and $\mathrm{Y}$ can fuse only if the linearization algorithm assigns them adjacent positions.

Fusion too may look like an inappropriate means for bringing Q and D together in (48) because they are clearly not adjacent in this phrase marker. But there is a way of making them adjacent, and that way, I will now show, is responsible for the fact that QR gets pronounced differently than Wh Movement.

\section{Deriving the Differences in Pronunciation}

I identified three ways, rephrased in (51), that QR gets linearized differently than Wh Movement. We are now ready to see how the representations for Wh Movement and QR in the previous section derive these differences.

(51) a. A Wh moved phrase is pronounced in its higher position, but a QR'd phrase is pronounced in its lower position.

b. Material in the higher position of Wh moved phrase is linearized to the left of the other position. Material in the higher position of a QR'd phrase is linearized to the right of the lower position (if it is linearized at all).

c. QR'd material must be semantically interpreted where it is spoken, but Wh moved material is able to be semantically interpreted in only its unspoken position.

Let's consider each of these in turn.

Nothing about the representation I have given Wh Movement will determine whether the whphrase is pronounced in its higher or lower position. To the extent that wh-in-situ questions, like that in (52), involve "covert" movement of the wh-phrase, this is a good result.

(52) Which woman bought which magazine?

\footnotetext{
${ }^{21}$ See Pranka (1983), Marantz (1988, 1984), Halle and Marantz (1993), Bobaljik (1995), Embick and Noyer (2001), Matushansky (2006) and references cited therein.
} 
Under the semantics I have sketched, both which woman and which magazine have moved in (52), and yet one gets linearized in its higher position and the other gets linearized in its lower position. We will not want the syntax of Wh Movement, then, to determine in which position a moved phrase is pronounced. The syntax provided here will permit the requisite flexibility.

The situation is different with QR. As noted above, if it's fusion that is responsible for mapping the D and Q parts of a QR'd expression onto the lexical item familiarly associated with quantificational nominals, then $\mathrm{QR}$ produces a representation in which the adjacency condition on fusion is (often) not met. I think we should expect that to produce an ungrammatical result. I speculate that there is a condition which requires the terminals in a phrase marker to be mapped onto matching morphology. That condition should require the $\mathrm{Q}$ holding $\forall$, for instance, to be expressed morphologically. But if the term that expresses $\forall-$ let's assume it's every — can only be inserted in a position where $\forall$ and the are fused, then this requirement will not be met in a structure formed by QR. I'll assume that another clause of the Principle of Full Interpretation is responsible for requiring terminals to get expressed morphologically. I will assume (53), then.

(53) a. Principle of Full Interpretation (morphology)

Every terminal in a phrase marker must be expressed morphologically.

b. English particular properties of determiners

Every QR'able determiner (e.g., every, many, etc.) can only insert into a position where the and Q fuse.

This will force Q to be fused with D; it cannot survive on its own. But the structures formed by QR prevent this, and therefore do not lead to a structure that can be grammatically expressed.

I suggest that this has the effect of forcing fusion to occur before QR builds the offending structure. Because fusion requires of the terms to be fused that they be adjacent, this will also require that the linearization algorithm be run on structures formed before $\mathrm{QR}$ has applied. (The linearization algorithm is what determines adjacency relations, so it will necessarily need to apply for fusion to occur.) That the linearization algorithm can apply mid-derivation has been argued for in Epstein and Seely (2002), Nissenbaum (2000a,b), Fox and Pesetsky (2004) and others. What I'm suggesting, then, is that this ability to linearize during the derivation is compelled by (53). And what we'll now see is that this in turn derives the fact that QR is "covert," as well as the other of its pronunciation peculiarities.

Consider, then, the step in the derivation of (48) that (54) represents.

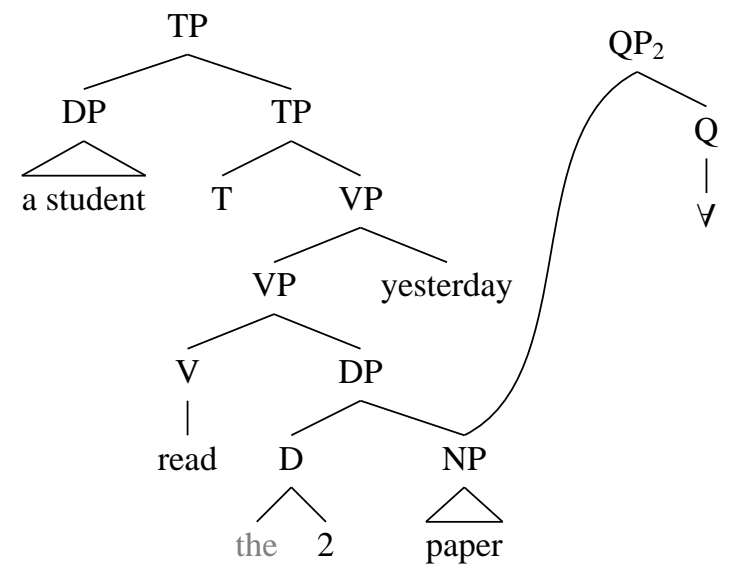


At this point in the derivation, everything that will be in the Quantificational DP and everything that will be in the TP that QR targets has been put together, but the QP and TP have not yet merged. This representation has two root nodes: TP and QP. If we define the linearization algorithm so that it runs on root nodes, then in this case it will apply to TP and QP independently and produce the ordered pairs in (55).

(55) a. The linearization of TP (= a student read D paper yesterday) is:

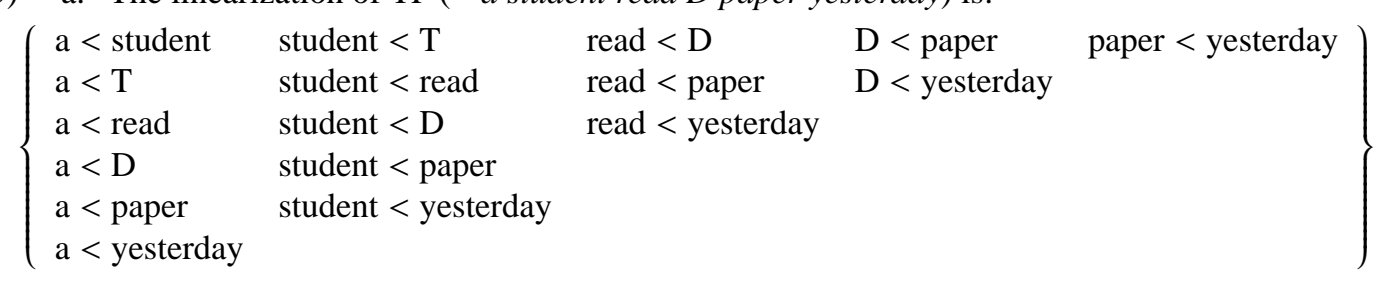

b. The linearization of $\mathrm{QP}=\forall<$ paper

These statements are the ones that English normally imposes on TPs and QPs that have the shapes in (54). In particular, they assume that the D and Q I have invented order themselves according to the recipes in (56).

(56) Linearizing QP puts Q before everything else in QP Linearizing DP puts D before everything else in DP

This merely assumes that these phrases are head initial in the same kind of way that determinerlike phrases seem to always be in English.

The linearization in (55) puts nothing between $\mathrm{D}$ and $\forall$, and this allows them to fuse. That is, there is nothing that follows $\mathrm{D}$ and precedes $\mathrm{Q}$ (or vice versa) in either of the linearizations in (55). ${ }^{22}$ Once they've fused and been mapped onto every, it is every that will occupy the positions assigned to D and $\forall$ in (55). After QP and TP have merged, no new ordering statements need to be added to meet the requirement of totality. That's because totality only requires that every vocabulary item in a phrase marker be assigned a position relative to every other vocabulary item, and that will be achieved by (55) (after D and Q fuse) for all the vocabulary items that will be matched to the terminals in (54). So (55) will be the linearization for the final representation $(=(48))$. (55) corresponds to the string in (57), which is precisely the right outcome.

(57) a student read every paper yesterday

The QR'd phrase is spelled out in its lower position, as desired. ${ }^{23}$

This effect was achieved by forcing the linearization algorithm to apply before the QP merges into the larger structure. As a consequence, the material that is in both the QP and the larger structure will get its position fixed relative to the rest of the material in the sentence "before"

\footnotetext{
${ }^{22}$ This relies on assuming that "adjacency" in (50) arises if the linearization algorithm puts nothing between the adjacent items. This is a sufficiently weak condition that one might worry that it brings with it unwelcome consequences. Jeroen van Craenenbroeck warns that this would allow fusion across great distances: as long as there is a derivation which, at some point, allows the two terms which are fused to be part of independent roots in the way that multidominant structures are, those terms could fuse. I am hoping that this danger is removed by Contiguity, which will prevent derivations with multidominant representations unless they are forced by whatever forces movement. There may be a real problem here.

${ }^{23}$ This way of making QR "covert" seems to predict that no language could have an overt version of QR. This has sometimes been claimed to arise, even in English (see Johnson (2000c), for instance).
} 
the QP's position in the larger structure can be computed. This is how the effect of making a QR'd term be spelled out in the lower position is achieved. In the illustrative example we just stepped through, for instance, the reason paper is linearized so that it precedes yesterday is that paper gains its position relative to yesterday when the linearization algorithm applies to TP after yesterday has been merged but before $\mathrm{QP}$ has been. Totality requires that this linearization include paper and yesterday, and the normal result delivered by the linearization algorithm is to put the vocabulary items in an object before the vocabulary items in an adjunct: so paper < yesterday gets produced. Similarly, the Q+D item in a QR'd expression gets spelled out in its lower position because its position is assigned before the QP has merged into the larger structure. Once Q and D fuse and are mapped onto the appropriate vocabulary item, that item's position will be assigned to the positions that $\mathrm{Q}$ and $\mathrm{D}$ each have. With respect to the material in the QP, that means that the vocabulary item will, like $\mathrm{Q}$, be forced to precede everything else in the QP and, like D, be forced to precede both everything else in the DP and everything that DP precedes. This puts every before both paper and yesterday.

For these effects to be sufficiently general, two things need to be ensured. First, it must be that the positions assigned by the linearization algorithm at some stage in the derivation cannot be later changed. That is an assumption about how the linearization algorithm applies that has been argued for elsewhere, most famously, perhaps, in Fox and Pesetsky (2004). This will guarantee that the positions assigned to D, Q and NP are all immutably determined by a structure that does not have the QP and the DP in the same root node.

The second thing that needs to be ensured is that the linearization algorithm is applied at the point in the derivation immediately before the QP has merged to the rest of the structure. That paper precedes yesterday in our example sentence arises because the TP containing paper also contains yesterday. If the linearization algorithm could apply before yesterday has been merged, then no ordering between paper and yesterday would have been established and, conceivably, a later application of the linearization algorithm could produce a different ordering between them. It is not clear to me what damage this would do in real live cases, but for safety's sake, I will block derivations of this sort with the constraint in (58). ${ }^{24}$

(58) Apply the linearization algorithm as late in the derivation as possible.

How to formulate (58) more precisely, and whether its consequences might follow from other components of the grammar, I'll leave unfinished. With these two additional assumptions in place, the syntax given here for QR derives the fact that a QR'd phrase is pronounced in its lower position.

Let's consider next how this system derives (51c).

(51c) QR'd material must be semantically interpreted where it is spoken, but Wh moved material is able to be semantically interpreted in only its unspoken position.

We've already seen how the case of Wh Movement works. An interrogative DP can be semantically interpreted entirely in its lower position, and yet be part of a phrase that the linearization algorithm puts in a different position. If the linearization algorithm aligns the material in which story about her so that it precedes everything else in the sentence - a consequence of the fact that the material in Specifier of CP is linearized at the leftmost edge of that CP - then (45) will map onto the right string.

\footnotetext{
${ }^{24}$ This is essentially Pesetsky's (1998) "Procrastinate" condition.
} 
(45)

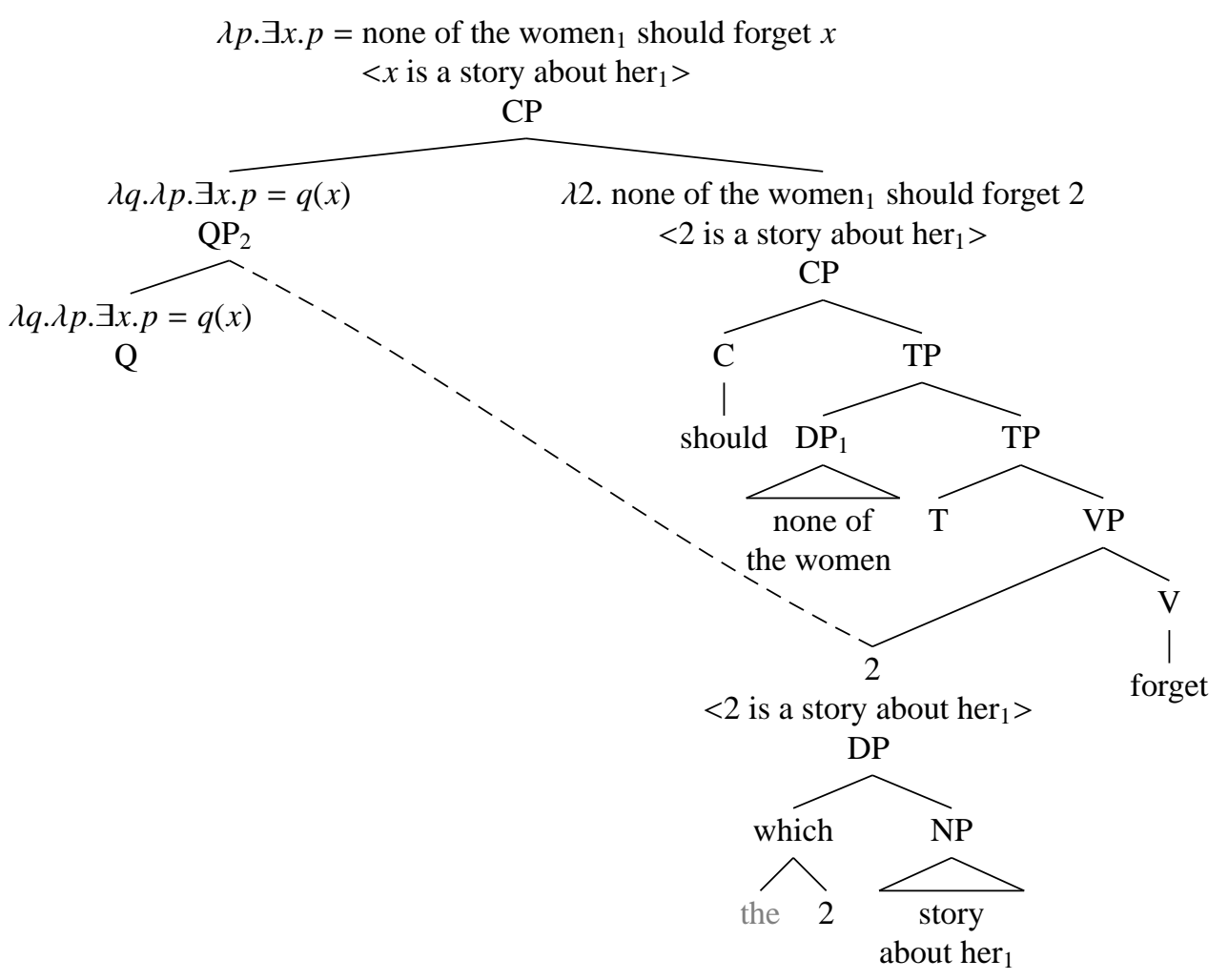

= Which story about her should none of the women forget?

In this way, then, an interrogative phrase can be pronounced in a position that it is not semantically interpreted in.

Let's consider why something parallel is not possible for QR. The case I used to demonstrate (51c) is (22), which, under a copy theory account of movement, gets the representation indicated.

(22) * I said that everyone you did $\triangle$ arrived.

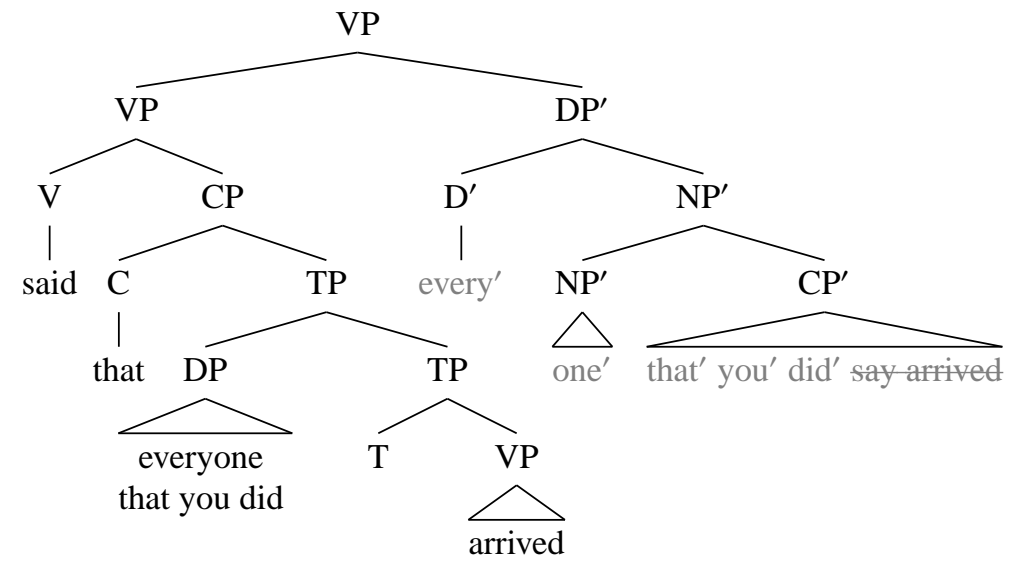


Because this representation does not resolve the ellipsis, we concluded that the relative clause in the lower copy must be semantically interpreted. But it is mysterious why the relative clause must be semantically interpreted in its lower position in this structure, since, in general, moved material can be semantically interpreted somewhere other than where it is pronounced. So this is what (51c) records: something about QR forces the relative clause to be semantically interpreted in its spoken position.

If QR is modeled with the multidominant representations proposed here, however, the string in (22) corresponds to the representation in (59).

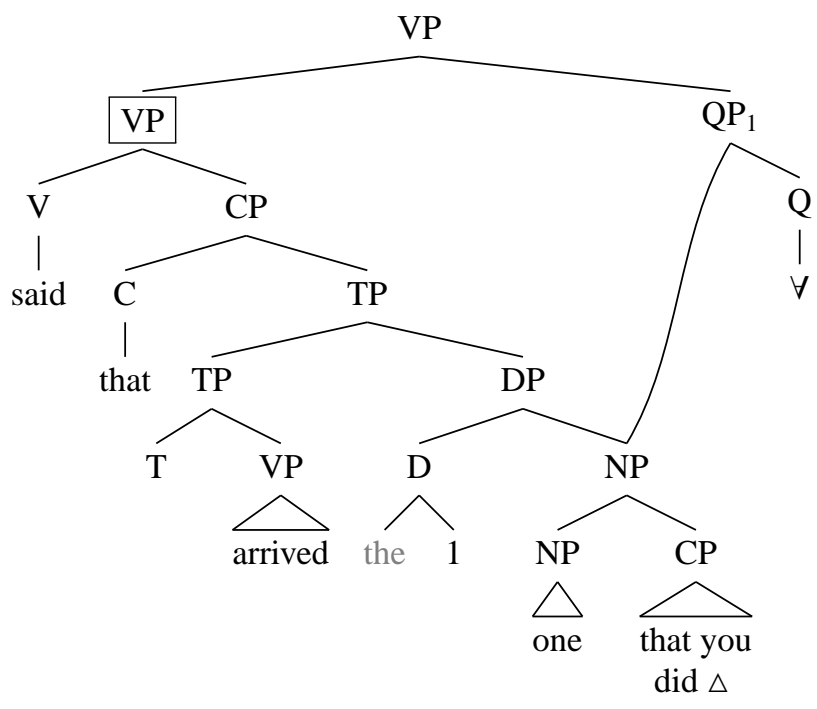

There is no mystery why this structure does not resolve the ellipsis. The ellipsis is structurally inside its antecedent: VP.

To see why (59) is the structure that corresponds to the string in (22), consider how the linearization algorithm will apply to it. As we've seen, the linearization algorithm must run before the QP is merged to VP in order for the conditions on fusion of D and Q to be met. So, the string associated with (59) will be built upon the output the linearization algorithm produces from applying to (60). 
(60)

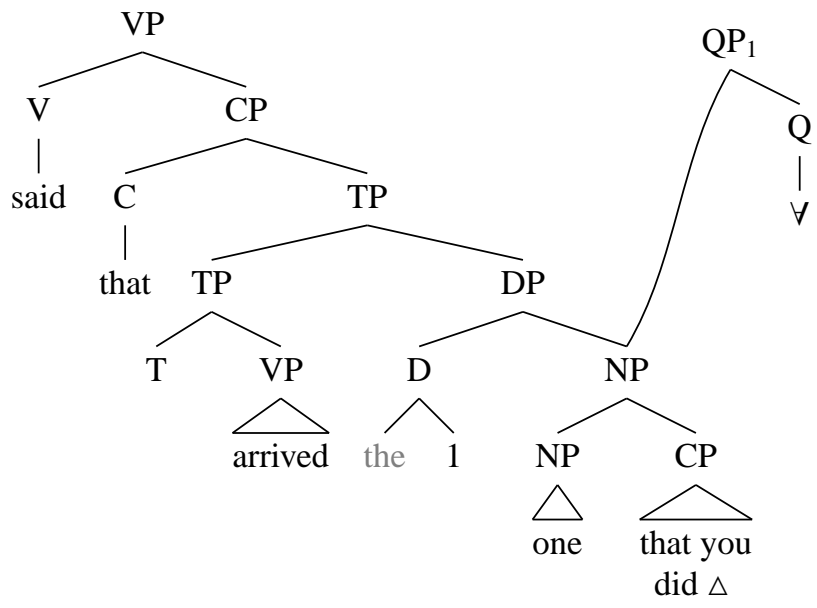

Those linearizations are (61).

(61) a. Linearization of VP (= said that $D$ one that you did arrived) is:

$\begin{array}{llll}\begin{array}{l}\text { said }<\text { that } \\ \text { said }<\mathrm{D}\end{array} & \begin{array}{l}\text { that }<\mathrm{D} \\ \text { that }<\text { one }\end{array} & \begin{array}{l}\mathrm{D}<\text { one } \\ \text { that }<\text { that }\end{array} & \begin{array}{l}\text { one }<\text { that } \\ \text { one }<\text { you }\end{array} \\ \text { said }<\text { one } & \text { one }<\text { did } \\ \text { said }<\text { that } & \text { that }<\text { you } & \mathrm{D}<\text { did } & \text { one }<\mathrm{T} \\ \text { said }<\text { you } & \text { that }<\text { did } & \mathrm{D}<\mathrm{T} & \text { one }<\text { arrived } \\ \text { said }<\text { did } & \text { that }<\mathrm{T} & \mathrm{D}<\text { arrived } & \\ \text { said }<\mathrm{T} & \text { that }<\text { arrived } \\ \text { said }<\text { arrived } \quad \text { one that you did }) \text { is: }\end{array}$
\[ \begin{array}{l}\forall<\text { one one }<\text { that that }<\text { you you }<\text { did } \\ \forall<\text { that one }<\text { you that }<\text { did } \\ \forall<\text { you one }<\text { did } \\ \forall<\text { did }\end{array} \]

$\mathrm{D}$ and $\mathrm{Q}$ are adjacent at this point in the derivation, so they can fuse and get matched to every. This means that every will fit into the string wherever D and Q jointly are mapped. When the linearization algorithm runs again, subsequent to merging QP and VP, no new ordered pairs will be introduced, and so we will get the simple union of these two linearizations. That corresponds to the string in (62).

(62) said that everyone that you did arrived

This is, indeed, the string that we want to map onto the structure that does not resolve the ellipsis.

To resolve the ellipsis requires a representation that involves "late merge" of the relative clause. In the remerge theory of movement offered here, this will look like (63). 
(63)

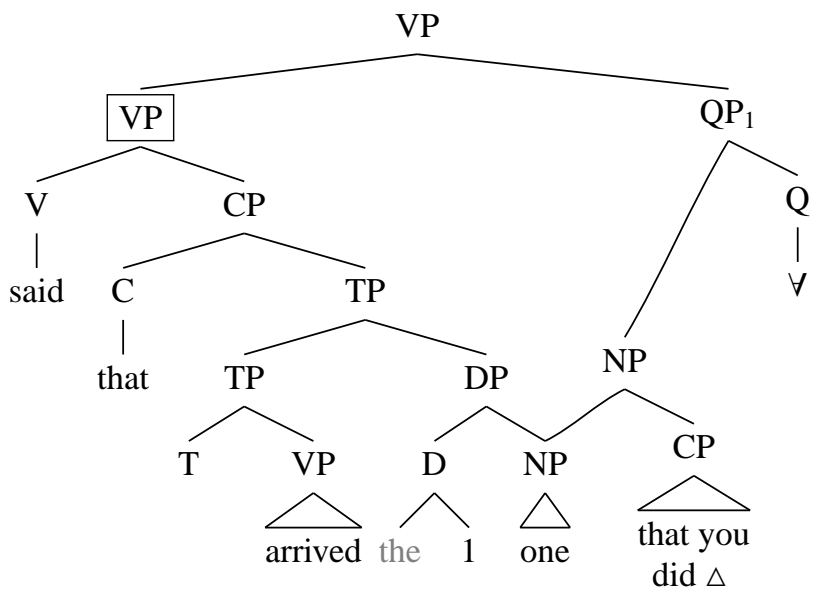

In this structure, as required, the relative clause is not within the VP that serves as antecedent. To see that this structure does not correspond to the string in (22), consider how the linearization algorithm will manufacture a linearization for it.

As always, the linearization algorithm will be forced to apply before the QP has merged into the larger structure. In this case, linearization will apply to (64).

(64)

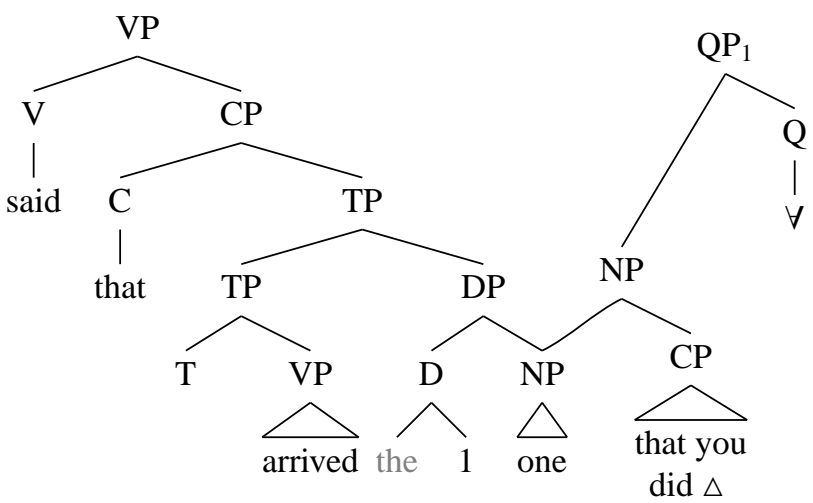

From (64), the linearization algorithm will produce (65).

(65) = said that everyone arrived \& everyone that you did

Linearization of $\mathrm{VP}=$

$\left\{\begin{array}{llll}\text { said }<\text { that } & \text { that }<\mathrm{T} & \mathrm{T}<\text { arrived } & \text { arrived }<\mathrm{D} \quad \mathrm{D}<\text { one } \\ \text { said }<\mathrm{T} & \text { that }<\text { arrived } & \mathrm{T}<\mathrm{D} & \text { arrived }<\text { one } \\ \text { said }<\text { arrived } & \text { that }<\mathrm{D} & \mathrm{T}<\text { one } & \\ \text { said }<\mathrm{D} & \text { that }<\text { one } & & \\ \text { said }<\text { one } & & & \end{array}\right\}$

Linearization of $\mathrm{QP}=$

$\left\{\begin{array}{ll}\forall<\text { one } & \text { one }<\text { that } \text { that }<\text { you you }<\text { did } \\ \forall<\text { that } & \text { one }<\text { you that }<\text { did } \\ \forall<\text { you } & \text { one }<\text { did } \\ \forall<\text { did } & \end{array}\right\}$ 
Notice that because the relative clause is not yet inside VP, it is not included in the string associated with VP. As a consequence, only the linearization of QP has information about where the relative clause will be positioned: it will follow everything else in QP. It is only after QP has merged with VP - to form (63) - that the linearization algorithm can order the material in the relative clause with the material in the VP. In order to satisfy Totality, the linearization algorithm will therefore have to apply again after (63) is formed.

The ordered pairs that this second run of the linearization algorithm will add to (65) must not only satisfy Totality, but they must also satisfy Antisymmetry and, to the extent possible, Contiguity. The best satisfaction of Contiguity will be linearizations that keep the material in the relative clause together and put it either all before the VP, or all after the VP. If the linearization algorithm puts the relative clause before the VP, the ordered pairs generated will include (66).

(66) one $<$ said, you $<$ said, ...

If these are added to the ordered pairs in (65), however, a violation of Antisymmetry will ensue: we'll have both one < said and said < one. For these reasons, the ordered pairs that the linearization algorithm generates when applied to (63) will add to (65) those in (67): ones in which the relative clause follows the VP.

(67) The new outputs from the linearization of $(63)=$

$$
\left\{\begin{array}{llll}
\text { said }<\text { that } & \text { that }<\text { that } & \mathrm{T}<\text { that } & \text { arrived }<\text { that } \\
\text { said }<\text { you } & \text { that }<\text { you } & \mathrm{T}<\text { you } & \text { arrived }<\text { you } \\
\text { said }<\text { did } & \text { that }<\text { did } & \mathrm{T}<\text { did } & \text { arrived }<\text { did } \\
\text { said }<\forall & \text { that }<\forall & \mathrm{T}<\forall & \text { arrived }<\forall
\end{array}\right\}
$$

Just as desired, this corresponds to the string in (68).

(68) ... said that everyone arrived that you did $\triangle$

For the relative clause to be structurally positioned outside the VP that is serving as the antecedent for the ellipsis it contains, it will necessarily be positioned linearly outside the string that corresponds to that VP. This result is perfectly general. We derive (51c): QR cannot put spoken material in a position where it is not semantically interpreted.

The ultimate cause for this difference between QR and Wh Movement is in the semantics. In Wh Movement, the DP that is in both positions is allowed to be semantically interpreted in only one of those positions. In QR, by contrast, the NP that is in both positions must be interpreted in both those positions. Because the linearization algorithm determines where material will get pronounced only on the basis of where, structurally, that material is, it emerges that wherever the material in a QR'd NP is pronounced will correspond to a position where it is semantically interpreted.

This leaves only (51b).

(51b) Material in the higher copy of Wh Movement is linearized to the left of the other copy. Material in the higher copy of QR is linearized to the right of the lower copy (if it is linearized at all).

Nothing about the proposal I've made for Wh Movement will derive the fact that when a moved wh-phrase is linearized in its higher position, it precedes everything in its sister. Unlike my inability to derive whether a wh-phrase in English is spoken in its higher or lower position, this may be a failure of the system. It does not appear that languages freely vary with regard to where 
moved wh-phrases get linearized. Dryer (2005), for instance, reports only a few languages out of his sample of 803 with an obligatory final position for interrogative phrases, while 241 require that interrogative phrases be initial, and 542 optionally position interrogatives in initial position. Deriving this trend is one reason to adopt the particular linearization algorithm in Kayne (1994), which is designed for this goal. Nothing in this paper helps get it.

But that the higher position of QR should, when containing something that is linearized, follow its sister does emerge from the syntax I've provided for QR. In stepping through how the linearization algorithm positions the late merged relative clause in (65), we saw not only that it must put that relative clause outside the phrase to which the QP merges, but also that it must put that relative clause to the right of the phrase to which the QP merges. This arises because the relative clause is forced to follow everything else within the QP that dominates it, and, at the same time, all the material in that QP gets linearized within the phrase to which the QP later merges. Thus, when the QP merges with some phrase, the relative clause it contains will have to linearize itself with respect to that phrase in the same way that it is linearized with respect to the rest of the QP's material inside that phrase. The reason relative clauses "move" to the right when they extrapose, then, is that English linearizes relative clauses at the right edge of the nominals they modify. That requirement will be carried over to how the relative clause is positioned in its extraposed position. This predicts that in languages that have QR like English does, but linearize relative clauses at the left edge of their nominals, we should see extraposed clauses showing up to the left of the nominals they are related to. I don't know if that prediction is borne out.

This way of deriving the rightwards direction of extraposition has another useful consequence. It correctly captures the fact that in English, the only material that can extrapose out of nominals is material that can be linearized at the right edge of those nominals - a generalization that Nissenbaum (2000b, p. $183 \mathrm{ff}$.) identifies and proposes an explanation for. Extraposition cannot, for instance, form (69a) from (69b).

(69) a. * I met every student yesterday new.

b. I met every new student yesterday.

(69a) would get the representation in (70).

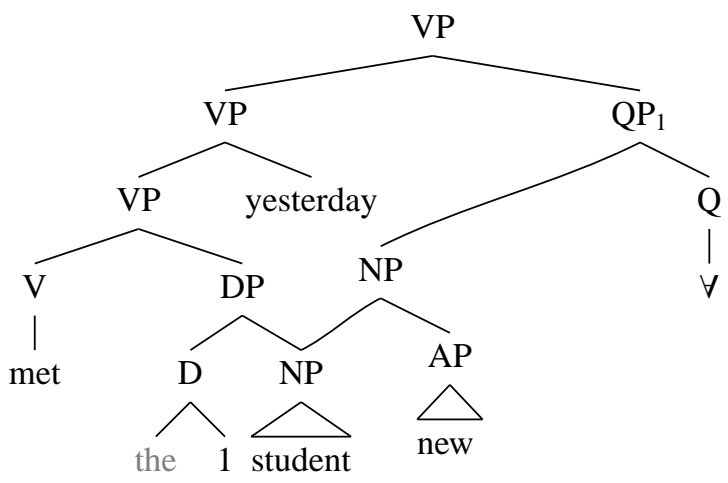

As in every example of QR, the linearization algorithm will run before QP has merged into the larger structure. In this case, then, the linearization algorithm will apply before QP and VP have merged. After fusion occurs, the linearization algorithm will produce from QP the ordered pairs that correspond to the string in (71), and from VP, it will produce ordered pairs that correspond to the string in (72). 
(71) every new student

(72) met every student yesterday

After QP has merged with the VP to form (70), the linearization algorithm will have to run again in order to ensure that Totality is obeyed. As in the case of an extraposed relative clause, this latter run has two choices: it may put new after the VP or before the VP. Unlike in the case of a relative clause, however, both of these choices violate Antisymmetry. If $n e w$ is positioned after the VP, then it will be positioned after student, and that is at odds with the previous run of the linearization algorithm, which positions new before student. If, instead, the choice is to put new before the VP, this will cause it to precede every (because every will be where D is), and again this will conflict with what the previous run of the linearization algorithm does. This effect arises for any material that gets linearized between the determiner and whatever shows up at the end of the DP. Only material at the very end of a DP can be extraposed without causing a conflict in the resulting linearization.

This solution to the problem of constraining extraposition from NP is in all its essentials just the one offered in Fox and Pesetsky (2009). The linearization scheme proposed in that talk also has the consequence that the way material is linearized within a DP must match how that material is linearized outside that DP when it is extraposed. My linearization scheme differs from theirs, as do my representations for $\mathrm{QR}$, so the difference in our accounts of this effect resides in its source. I am otherwise simply mimicking their account.

All the differences in how Wh Movement and QR lead to strings have now been derived. QR is "covert" because the way its determiner is put together forces it to be linearized before the movement has taken place. And for the same reason, the linearization algorithm is triggered in such a way that the only material that can be "extraposed" from an NP is material that can be linearized into its extraposed position in the same way that it linearizes in the NP it is extraposed from. For English particular reasons, this means that extraposition will be rightwards. And, finally, these particularities of $\mathrm{QR}$ are linked to the fact that the two parts that combine into the QR'd determiner have a semantics that requires them to share an NP. This part of the proposal derives the fact that material that is QR'd is always semantically interpreted in the position it is spoken in.

\section{Summary}

I've provided a way of expressing the "remerge" model of movement that smooths its interface with the semantics. That way causes the DPs that undergo Wh Movement and QR to have two head-like elements associated with them that combine to form what we see as the determiner of the moved phrase. One of those head-like elements is a kind of definite determiner; it heads the phrase that is interpreted in the "trace" position. The other head-like element is a binder that binds a variable associated with the definite determiner in the "trace" position. The reason, then, that a moved phrase seems to have one meaning in its binder position and another meaning in its bound position is because there are actually two, separate, things serving those roles in the syntax.

But those two parts get mapped onto one lexical item. In the case of Wh movement, it is the wh-determiner. In the case of QR, it is the quantifier. In English, then, the reason for the existence of these movement operations is that there is one lexical item that is charged with expressing both of the binder/bindee expressions. In Wh Movement this is achieved by putting the bound determiner within the scope of the binder element and letting AGREE cause the form 
of the lower determiner to be which (or some other wh-determiner). In QR, however, the bound determiner cannot be put within the scope of the binder element because of how their semantics works. The mechanism of letting two terminals map onto one morphological form that AGREE describes is therefore not available to QR'd expressions. Instead, the other widely known method of achieving this end is used: fusion. The conditions on fusion have a multitude of consequences for how the structures produced by $\mathrm{QR}$ are pronounced. They are responsible for why $\mathrm{QR}$ is largely "covert," and for why QR is rightwards when it isn't covert.

I've focused here on the narrow problem of deriving differences in how two instances of movement $-\mathrm{QR}$ and Wh Movement - get pronounced. But the general approach to movement sketched here provides, perhaps, a way of explaining why movement exists and where it arises. We can think of movement as departures from the condition of Contiguity that arise when other, more important, requirements demand it. In Wh Movement and QR, those demands are made by the morphology and the semantics. In Wh Movement this traces back to the fact that the English lexicon only provides single lexical items to express both the question morpheme and the interrogative determiner that make up constituent questions. The question morpheme must combine semantically with the clause that functions as the question, and the interrogative determiner must be wherever the bound argument is. But for these two pieces to be positioned syntactically so that they can map onto one lexical item, remerge is required. Similarly for QR, the English lexicon only provides single words to express both the variable definite determiner and the quantifier that form nominal quantification. Again, for these two pieces to be positioned syntactically so that they can map onto one lexical item, and also produce a well-formed semantic interpretation, remerge is required. In both cases, the semantics requires two things to be in distant syntactic positions and the morphology requires those things to be in proximate syntactic positions. Remerge provides a way of meeting both requirements.

Movement, then, could be seen as arising just when problems of this sort find a solution through remerge. The particular way in which movement relations get semantically interpreted will depend on how the problem remerge solves interacts with the semantics. In the cases examined here, there are two meaningful terms that need to share material, and remerge is triggered. Because both of these terms have the particular denotation that they do, the movement relation invokes the binder-bindee relation that I have tried to model. But there are other sorts of semantic relations that movement invokes. There are cases of movement, for instance, that seem to be, in part or in whole, semantically vacuous. Many instances of verb movement ${ }^{25}$ some instances of A movement, ${ }^{26}$ and certain cases of predicate movement ${ }^{27}$ illustrate these possibilities. What the proposals here lead one to expect of these cases is that the term in the higher position which is causing the problem that remerge solves is not a term whose semantics is at play. Instead, perhaps, it is something that is responsible for forcing the remerged term to be linearized according to its higher position. In general, the proposals here lead to the expectation that the range of semantic outcomes movement has should match the kinds of problems that it solves. Whether the proposals I have made here about Wh Movement and QR are correct should be judged by how the picture of movement they illustrate fare in these, and the whole gamut of other, movement relations. There are plenty of problems, but I am hopeful.

\footnotetext{
${ }^{25}$ See Lechner (2007).

${ }^{26}$ See Sauerland and Elbourne (2002) and Lechner (1998).

${ }^{27}$ See Huang (1993), Takano (1995), Heycock (1995) and Romero (1998).
} 


\section{References}

Adger, D., Ramchand, G., 2005. Merge and move: Wh-dependencies revisited. Linguistic Inquiry 36 (2), 161-193.

Baltin, M., 1987. Do antecedent-contained deletions exist? Linguistic Inquiry 18 (4), 579-596.

Barss, A., 1986. Chains and anaphoric dependence: On reconstruction and its implications. Ph.D. thesis, Massachusetts Institute of Technology.

Beck, S., 2006. Intervention effects follow from focus interpretation. Natural Language Semantics 14 (1), 1-56.

Beghelli, F., 1993. A minimalist approach to quantifier scope. In: Schafer, A. J. (Ed.), Proceedings of the North East Linguistic Society 23. Graduate Linguistic Student Association, University of Ottawa, pp. 65-80.

Beghelli, F., 1995. The phrase structure of quantifier scope. Ph.D. thesis, UCLA, Los Angeles.

Bobaljik, J., 1995. Morphosyntax: The syntax of verbal inflection. Ph.D. thesis, Massachusetts Institute of Technology, Cambridge.

Butler, J., 2004. Phase structure, phrase structure, and quantification. Ph.D. thesis, The University of York.

Cable, S., 2007. The grammar of Q: Q-particles and the nature of wh-fronting, as revealed by the wh-questions of Tlingit. Ph.D. thesis, Massachusetts Institute of Technology, Cambridge, Massachusetts.

Cable, S., 2008. There is no such thing as pied-piping, unpublished paper, University of Massachusetts at Amherst.

Cable, S., 2010a. Against the existence of Pied-Piping: Evidence from Tlingit. Linguistic Inquiry 41 (4), 563-594.

Cable, S., 2010b. The Grammar of Q: Q-Particles, Wh-Movement and Pied-Piping. Oxford University Press.

Chierchia, G., 1992. Questions with quantifiers. Natural Language Semantics 1 (2), 181-234.

Chomsky, N., 1995. The minimalist program. MIT Press, Cambridge, Massachusetts.

Citko, B., 2005. On the nature of merge: External merge, internal merge, and parallel merge. Linguistic Inquiry 36 (4), 475-496.

Dryer, M. S., 2005. Position of interrogative phrases in content questions. In: Haspelmath, M., Dryer, M. S., Comrie, B. (Eds.), The World Atlas of Language Structures. Oxford University Press, Oxford, pp. 378-379.

Elbourne, P. D., 2005. Situations and Individuals. MIT Press.

Embick, D., Noyer, R., 2001. Movement operations after syntax. Linguistic Inquiry 32 (4), 555-595.

Engdahl, E., 1980. The syntax and semantics of questions in Swedish. Ph.D. thesis, University of Massachusetts, Amherst, Massachusetts.

Engdahl, E., 1986. Constituent Questions. D. Reidel Publishing Company, Dordrecht, The Netherlands.

Epstein, S. D., Seely, T. D. (Eds.), 2002. Derivation and explanation in the Minimalist Program. Blackwell Publishing, Malden, Massachusetts.

Fanselow, G., Ćavar, D., 2001. Remarks on the economy of pronunciation. In: Müller, G., Sternefeld, W. (Eds.), Competition in Syntax. Mouton de Gruyter, Berlin, pp. 107-150.

Fitzpatrick, J., Groat, E., March 2005. The timing of syntactic operations: Phases, c-command, remerger, and Lebeaux effects, paper presented at ECO5.

Fox, D., 1999. Reconstruction, binding theory, and the interpretation of chains. Linguistic Inquiry 30 (2), 157-196.

Fox, D., 2002. Antecedent-contained deletion and the copy theory of movement. Linguistic Inquiry 33 (1), 63-96.

Fox, D., 2003. On logical form. In: Hendrick, R. (Ed.), Minimalist Syntax. Blackwell Publishers, Oxford, pp. 82-123.

Fox, D., Nissenbaum, J., 1999. Extraposition and scope: a case for overt QR. In: Bird, S., Carnie, A., Haugen, J. D., Norquest, P. (Eds.), Proceedings of the West Coast Conference on Formal Linguistics 18. Cascadilla Press, Somerville, Massachusetts, pp. 132-144.

Fox, D., Pesetsky, D., 2004. Cyclic linearization of syntactic structure. Theoretical Linguistics 31 (1-2), 1-46.

Fox, D., Pesetsky, D., July 2009. Rightward movement, covert movement, and cyclic linearization, talk delivered at Ben Gurion University.

Frampton, J., 2004. Copies, traces, occurrences, and all that: Evidence from Bulgarian multiple wh-phenomena, unpublished manuscript, Northeastern University.

Gärtner, H.-M., 1997. Generalized transformations and beyond. Ph.D. thesis, University of Franfurt/Main.

Gärtner, H.-M., 2001. Phase-linking meets Minimalism. In: Proceedings of WCCFL 18.

Hagstrom, P., 1998. Decomposing questions. Ph.D. thesis, Massachusetts Institute of Technology, Cambridge, Massachusetts.

Hagstrom, P., 2000. The movement of question particles. In: Hirotani, M., Coetzee, A., Hall, N., Kim, J.-y. (Eds.), Proceedings of the North East Linguistic Society. Graduate Linguistic Student Association, Rutgers University, pp. $275-286$.

Halle, M., Marantz, A., 1993. Distributed morphology and the pieces of inflection. In: Hale, K., Keyser, S. J. (Eds.), The View from Building 20. MIT Press, Cambridge, Massachusetts, pp. 111-176.

Hamblin, C., 1973. Questions in Montague grammar. Foundations of Language 10 (1), 41-53.

Heim, I., Kratzer, A., 1998. Semantics in generative grammar. Blackwell, Malden, MA.

Heycock, C., 1995. Asymmetries in reconstruction. Linguistic Inquiry 26 (4), 547-570. 
Huang, C.-T. J., 1993. Reconstruction and the structure of VP: some theoretical consequences. Linguistic Inquiry 24 (1), $103-138$.

Johnson, K., 2000a. Few dogs eat Whiskers or cats Alpo. In: Kusumoto, K., Villalta, E. (Eds.), University of Massachusetts Occasional Papers (23). UMOP, Amherst, MA, pp. 47-60.

Johnson, K., 2000b. Gapping determiners. In: Schwabe, K., Zhang, N. (Eds.), Ellipsis in conjunction. Niemeyer, Tübingen, pp. 95-115.

Johnson, K., 2000c. How far will quantifiers go? In: Martin, R., Michaels, D., Uriagereka, J. (Eds.), Step by Step. MIT Press, Cambridge, Massachusetts, pp. 187-210.

Karttunen, L., 1977. Syntax and semantics of questions. Linguistics and Philosophy 1 (1), 3-44.

Kayne, R. S., 1994. The Antisymmetry of Syntax. MIT Press, Cambridge, Massachusetts.

Kishimoto, H., 2005. Wh-in-situ and movement in Sinhala questions. Natural Language and Linguistic Theory 23 (1), $1-51$.

Kitahara, H., 1996. Raising Q without QR. In: Abraham, W., Epstein, S. D., Thráinsson, H., Zwart, C. J.-W. (Eds.), Minimal Ideas. John Benjamins Publishing Company, Amsterdam.

Koopman, H., 1984. The Syntax of Verbs. Foris Publications, Dordrecht, The Netherlands.

Kratzer, A., 2005. Indefinites and the operators they depend on: From Japanese to Salish. In: Carlson, G. N., Pelletier, F. J. (Eds.), Reference and Quantification: The Partee Effect. CSLI Publications, pp. 113-142.

Kratzer, A., Shimoyama, J., 2002. Indeterminate pronouns: The view from Japanese. In: Otsu, Y. (Ed.), Proceedings of the Tokyo conference on psycholinguistics. Vol. 3. Hituzi Syobo, Tokyo, pp. 1-25.

Lebeaux, D., 1990. Relative clauses, licensing, and the nature of the derivation. In: Carter, J., Rose-Marie, D., Philip, B., Sherer, T. (Eds.), Proceedings of the North East Linguistic Society 20. Graduate Linguistic Student Association, University of Massachusetts at Amherst, pp. 318-332.

Lechner, W., 1998. Two kinds of reconstruction. Studia Linguistica 52 (3), 276-310.

Lechner, W., 2007. Interpretive effects of Head Movement.

Marantz, A., 1984. On the Nature of Grammatical Relations. MIT Press, Cambridge, Massachusetts.

Marantz, A., 1988. Clitics, morphological merger, and the mapping to phonological structure. In: Hammond, M., Noonan, M. (Eds.), Theoretical Morphology: Approaches in Modern Linguistics. Academic Press, San Diego, California, pp. 253-270.

Matthewson, L., 2001. Quantification and the nature of crosslinguistic variation. Natural Language Semantics 9 (2), $145-189$.

Matushansky, O., 2006. Head movement in linguistic theory. Linguistic Inquiry 37 (1), 69-109.

Nissenbaum, J., 2000a. Covert movement and parasitic gaps. In: Hirotani, M., Coetzee, A., Hall, N., Kim, J.-y. (Eds.), Proceedings of the North East Linguistic Society. Graduate Linguistic Student Association, Rutgers University, pp. 541-556.

Nissenbaum, J., 2000b. Investigations of covert phrase movement. Ph.D. thesis, Massachusetts Institute of Technology, Cambridge, Massachusetts.

Nunes, J., 1999. Linearization of chains and phonetic realization of chain links. In: Epstein, S., Hornstein, N. (Eds.), Working minimalism. MIT Press, Cambridge, Massachusetts, pp. 217-249.

Nunes, J., 2001. Sideward movement. Linguistic Inquiry 32 (2), 303-344.

Nunes, J., 2004. Linearization of Chains and Sideward Movement. Linguistic Inquiry Monographs. MIT Press, Cambridge, Massachusetts.

Pesetsky, D., 1998. Some optimality principles of sentence pronunciation. In: Barbosa, P., Fox, D., Hagstrom, P., McGinnis, M., Pesetsky, D. (Eds.), Is the Best Good Enough? MIT Press, Cambridge, Massachusetts, pp. 337-384.

Pranka, P., 1983. Syntax and word formation. Ph.D. thesis, Massachusetts Institute of Technology, Cambridge, Massachusetts.

Reinhart, T., 1997. Quantifier scope: How labor is divided between QR and choice functions. Linguistics and Philosophy 20 (4), 335-397.

Reinhart, T., 1998. Wh-in-situ in the framework of the Minimalist Program. Natural Language Semantics 6 (1), 29-56.

Reinhart, T., 2006. Interface Strategies. MIT Press.

Riemsdijk, H. v., Williams, E., 1986. Introduction to the Theory of Grammar. MIT Press.

Romero, M., 1998. Focus and reconstruction effects in wh-phrases. Ph.D. thesis, University of Massachusetts, Amherst.

Rullmann, H., Beck, S., 1998. Presupposition projection and the interpretation of which-questions. In: Strolovitch, D., Lawson, A. (Eds.), Proceedings of SALT VIII. CLC Publications, Ithaca, NY, pp. 215-232.

Sauerland, U., 1998. The meaning of chains. Ph.D. thesis, Massachusetts Institute of Technology, Cambridge, Massachusetts.

Sauerland, U., 2003. A new semantics for number. In: Proceedings of SALT 13. CLC Publications, Cornell University, Ithaca, NY, pp. 258-275.

Sauerland, U., 2004. The interpretation of traces. Natural Language Semantics 12, 63-127.

Sauerland, U., Elbourne, P., 2002. Total reconstruction, PF-movement, and the derivational order. Linguistic Inquiry 
33 (2), 283-319.

Sportiche, D., 2003. Reconstruction, binding and scope, unpublished manuscript, University of California, Los Angeles. Starke, M., 2001. Move dissolves into merge: A theory of locality. Ph.D. thesis, University of Geneva.

Sternefeld, W., 2001. Partial movement constructions, pied-piping and higher order choice functions. In: Féry, C., Sternefeld, W. (Eds.), Audiatur Vox Sapientiae. A Festschrift for Arnim von Stechow. Acadamie Verlag.

Szabolcsi, A., 1997. Ways of scope taking. Kluwer Academic Publishers, Dordrecht ; Boston ; London.

Takano, Y., 1995. Predicate fronting and internal subjects. Linguistic Inquiry 26 (2), 327-340.

Tiedeman, R., 1995. Some remarks on antecedent contained deletion. In: Haraguchi, S., Funaki, M. (Eds.), Minimalism and Linguistic Theory. Hituzi Syobo, Tokyo, pp. 67-103.

Williams, E., 1986. A reassignment of the functions of LF. Linguistic Inquiry 17 (2), 264-300.

Williams, E., 1988. Is LF distinct from S-structure? a reply to May. Linguistic Inquiry 19 (1), 135-146. 